\title{
CIRURGIA DOS CATETERES DE LONGA PERMANÊNCIA(CLP) NOS CENTROS DE TRANSPLANTE DE MEDULA ÓSSEA
}

\author{
SURGERY OF LONG-TERM CATHETERS (LTC) IN A BONE MARROW TRANSPLANTATION CENTER
}

Marcos Pires e Albuquerque

Especialista em Cirurgia Oncológica pela Sociedade Brasileira de Oncologia Cirúrgica (SBOC), Sociedade Brasileira de Cancerologia (SBC) e Associação Médica Brasileira (AMB). Cirurgião responsável pelo Setor de Acesso Vascular Prolongado do Centro Nacional de Transplante de Medula Óssea (CEMO) do Instituto Nacional de Câncer (INCA) - Praça Cruz Vermelha, 23 - Rio de Janeiro - RJ CoRRESPondÊnCIA: Rua Jerson Pompeu Pinheiro, 270. 22793-317 Rio de Janeiro - RJ. e-mail: mpires@marcospires.med.br

Pires e Albuquerque M. Cirurgia dos cateteres de longa permanência (CLP) nos Centros de Transplante de Medula Óssea. Medicina (Ribeirão Preto) 2005; 38 (2): 125-142.

RESUMO: O capítulo disserta sobre a utilização de Cateteres de Longa Permanência (CLP) num Centro de Transplante de Medula Óssea (CTMO), abordando seus aspectos cirúrgicos com o objetivo de preparar cirurgiões para o enfrentamento de pacientes hematológicos graves, seja no preparo para um TMO ou em situações complexas durante ou após o transplante.

Baseado numa experiência de 2.000 cateterismos executados pelo autor no Instituto Nacional de Câncer (INCA) é intencionado, numa narrativa didática para jovens cirurgiões, a dar orientação da prática cirúrgica necessária para o sucesso da implantação destes cateteres em pacientes de CTMOs.

São mostrados e discutidos aspectos inerentes ao cateter em si, como escolha de tipos e modelos, suas indicações, as técnicas cirúrgicas a serem adotadas normalmente (com a descrição detalhada do acesso jugular interno), as situações difíceis com questões relevantes à anatomia do mediastino com seus possíveis obstáculos e a forma de vence-los, e finalmente, os resultados e as complicações advindas do uso destes sistemas especificamente em pacientes de um CTMO.

Descritores: Cateterismo Venoso Central. Cirurgia. Cateter Venoso Central de Longa Permanência. Quimioterapia do Câncer. Transplante de Medula Óssea. Neoplasia.

"Este capítulo é dedicado aos jovens cirurgiões interessados no suporte cirúrgico para os Centros de Transplante de Medula Óssea “.

\section{1- CONCEITO}

Inicialmente descrito por Broviac ${ }^{1}$, o Cateter de Longa Permanência (CLP) é uma estrutura tubular, de diâmetro variado, confeccionado em silicone, e que uma vez introduzido no sistema vascular (venoso ou arterial) tem por objetivo permitir e manter um acesso profundo por longo período de tempo, recebendo periodicamente manuseios para aspiração sanguínea e administração de medicamentos.

Conforme já descrevemos ${ }^{2}$, três questões são básicas e necessárias para seu sucesso: 1) A técnica de implantação cirúrgica, 2) o manuseio (ou manipulação) e 3) a sua manutenção.

Neste capítulo vamos abordar os aspectos cirúrgicos relevantes da utilização desses sistemas em pacientes de um Centro de transplante de medula óssea (CTMO). 


\section{2- INDICAÇÃO DO USO DE CLP}

O CLP está indicado em todo e qualquer paciente necessitado de uma venóclise prolongada, seja para administração de medicamentos ou coleta sanguínea.

Num CTMO, os CLPs têm uma importância capital, pois é através deles que fazemos todo o tratamento. A sua implantação é o primeiro ato médico para dar início ao transplante e deverá permanecer em uso por cerca de 60 dias, desde o período de internação até o ambulatorial pós-transplante.

\section{3- TIPOS DE CLP}

Existem basicamente 2 tipos de cateteres. Os chamados Semi-implantáveis (SI) e os Totalmente implantáveis (TI). Cada tipo com vários modelos e diâmetros que variam entre 6 e 14 Fr. A diferença entre eles está na porção distal, isto é, no ponto onde é realizada a manipulação.

Os cateteres do tipo TI (Figura 1, B), como o nome diz, são sistemas que ficam totalmente embutidos no organismo humano e apresentam 2 segmentos: Um distal, intravascular e outro proximal, subcutâneo. A porção subcutânea termina num reservatório fechado, sem comunicação com o meio externo e, para ser acessado, necessita punção dérmica com agulhas próprias do tipo chamado Hubber. São indicados nos casos onde a manipulação é periódica, intermitente mas de curta duração. Permitem períodos de repousos (sem punções) prolongados (acima de 30 dias) e são ideais para as quimioterapias cíclicas geralmente realizadas para os tumores sólidos. Dispensam o uso de curativos e em nada restringem os afazeres diários dos pacientes. Consideramos um sistema confortável, prático e confiável, com permanência em algumas pessoas, por mais de 3 anos.

Os cateteres do tipo SI são sistemas com 3 segmentos (Figura 1, A). O primeiro (distal) é intravascular, o segundo (intermediário) é subcutâneo e o terceiro (proximal) é externo. Neste modelo a fixação ao organismo humano é feita através de uma reação fibrosa provocada entre o tecido gorduroso subcutâneo e uma pequena tira de Dacron ${ }^{\circledR}$, que chamaremos de "cuff", colada externamente ao cateter. Esta reação porém não é imediata, necessitando um período de maturação em torno de 3 a 4 semanas para se completar, até lá devem ser fixados por ponto na pele. São indicados para infusões prolongadas e freqüen- tes, portanto ideais para os TMO onde o manuseio é praticamente ininterrupto, em média por 60 dias.

O material utilizado na confecção de um CLPé o silicone médico ${ }^{1,3}$ que é estrudado (industrialização) numa composição com cerca de $4 \%$ de bário, a fim de torná-lo rádio-opaco para permitir visualização radiológica.

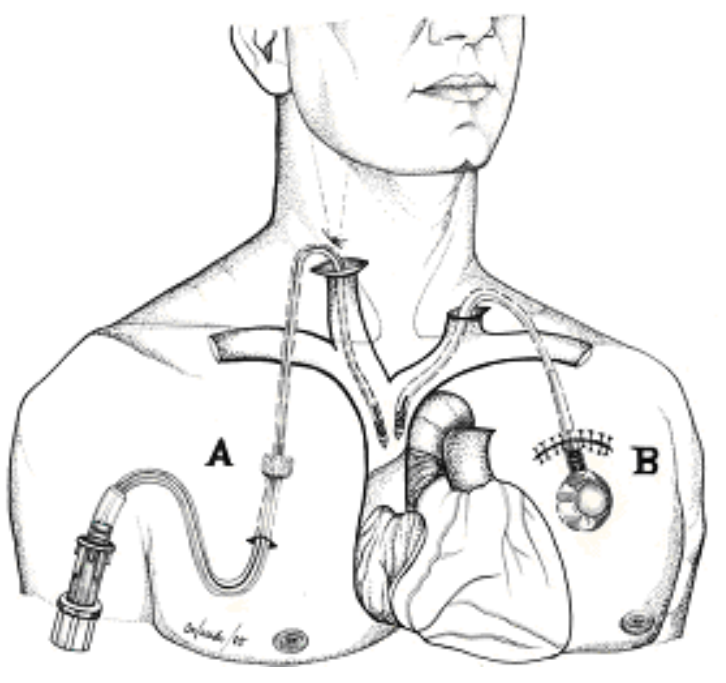

Figura 1: A- Cateter $\mathrm{SI}$, com seus 3 segmentos, exteriorizado na região torácica anterior direita. Observamos o "cuff" de fixação posicionado no subcutâneo cerca de $2 \mathrm{~cm}$ acima do ponto de inserção. B- Cateter TI com reservatório subcutâneo posicionado no subcutâneo à esquerda. Para acessá-lo é necessário punção através da pele com agulhas especiais.

O CLP utilizado para um TMO é do tipo SI, mas com duplo lúmen (conhecidos como cateter de Hickman $^{3}$ ), geralmente com diâmetro total de 9 a 9.6 Fr. para os adultos e 6.6 a 7 Fr. para as crianças com até 12 anos. O sistema de duplo lúmen permite utilizar uma via para infusão de medicamentos e a outra para coleta sanguínea, pois sem resíduos de soluções ou medicamentos em sua parede oferece maior segurança no resultado.

Nos transplantes autólogos, quando é permitido realizar a coleta de células por aférese periférica, podemos usar o mesmo cateter para o transplante subsequiente. Nestes casos o CLP indicado deve ter diâmetro entre 12 e 14 Fr para permitir um fluxo satisfatório na máquina de coleta.

\section{4- ASPECTOS CLÍNICOS}

No CTMO, a primeira ação preparatória ao transplante é a implantação do CLP. Assim o cirur- 
gião deve considerar que naquele momento, em princípio, está diante da melhor condição clínica do paciente. A partir daí, até o final do tratamento, complicações poderão surgir e a substituição de um cateter, se vier a ser necessária no período per-transplante, será feita em condições mais desfavoráveis, com maior morbidade e deve ser evitada, porém não é rara.

No CEMO, cerca de $6 \%$ dos pacientes no período per-transplante necessitaram substituição do cateter.

Diante desta incidência, nos acostumamos a uma afirmativa: - "Num CTMO é prudente guardar acessos mais fáceis para momentos mais complicados". Se há boas condições clínicas do paciente no pré-transplante e um acesso mais simples e menos mórbido pode ser facilmente executado, preferimos "guardá-lo" para um futuro incerto, optando inicialmente por um acesso mais mórbido como por exemplo aqueles por punção. A isto, conforme veremos na sequiência do capítulo, chamamos de tática da escolha de acesso porque num cateterismo para administração de medicamentos, não há contra-indicações e muitas vezes a condição clínica do paciente é desfavorável para uma intervenção cirúrgica ${ }^{4}$.

$\mathrm{O}$ maior fator complicador numa cirurgia em paciente hematológico é sua condição de hemostasia. Os riscos de sangramentos e hematomas na área operatória são significativos ${ }^{5}$. No CEMO-INCA, cerca de 11,64\% (Quadro 1) dos pacientes tiveram que ser submetidos à implantação de CLP com menos de 10.000 plaquetas por $\mathrm{mm}^{3}$.

Acessos por punções, sejam da veia subclávia (VSC) ou da veia jugular interna (VJI) são mais rápidos e menos agressivos, com um consumo de plaquetas menor do que por dissecção, portanto podem ser tentadas, desde que criteriosamente, em vigência de plaquetopenias severas. Vale muita a experiência do cirurgião em avaliar e selecionar esses casos, pois uma punção inadvertida da artéria subclávia ou, principalmente, carótida pode ocasionar grandes hematomas com consequiências que podem comprometer todo o transplante.

\section{5- ASPECTOS CIRÚRGICOS}

\section{1- Anatomia do mediastino ântero-superior}

Todo cateterismo venoso central significa posicionar a ponta de um cateter ao nível da veia cava superior (VCS), portanto o conhecimento anatômico do compartimento venoso supracardíaco é fundamental para a implantação cirúrgica.

Conforme observamos na Figura 2, este compartimento se localiza no mediastino ântero-superior e está representado pela união das veias jugulares internas com as veias subclávias. Elas compõem os chamados ângulos venosos braquiocefálicos direito e esquerdo que se unem entre si através da veia inominada formando a VCS, um tronco venoso vertical e extrapericárdico, com cerca de 6 a $8 \mathrm{~cm}$ de comprimento ${ }^{6}$.

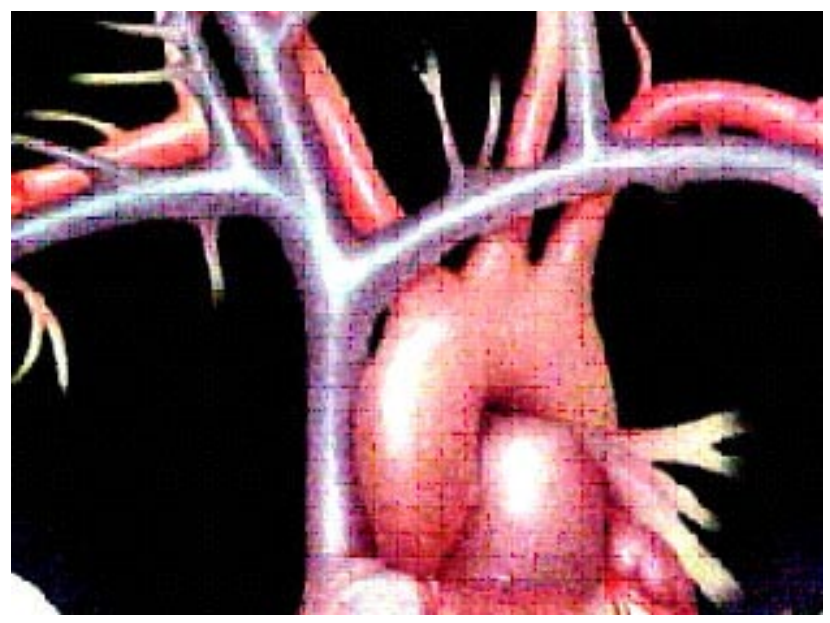

Figura 2 - Anatomia do compartimento vascular supracardíaco mostrando os troncos braquiocefálicos, a veia inominada para formação da VCS.

Um correto posicionamento significa introduzir a ponta do cateter no segmento inferior da VCS. Esta aferição, é feita durante a visão fluoroscópica peroperatória, e está representada por sua relação com a carina, devendo ficar cerca de 4 a $7 \mathrm{~cm}$ abaixo dela (Figura 3).

Ao obter este posicionamento porém, o cirurgião se defronta muitas vezes com fatores complicadores que precisam ser considerados e convenientemente vencidos para obtenção do êxito cirúrgico.

Para tal, primeiramente devemos considerar os ângulos anatômicos formados entre os ângulos venosos braquiocefálicos e a VCS. Pelo lado direito, mediante um acesso através da VSCD, nos defrontamos com um ângulo mais agudo para descer para a VCS (Figura 4 A), o que pode dificultar o posicionamento do cateter. Não raramente, ele pode "seguir em frente" e cruzar para o lado esquerdo através da veia inominada (Figura 4 B). 


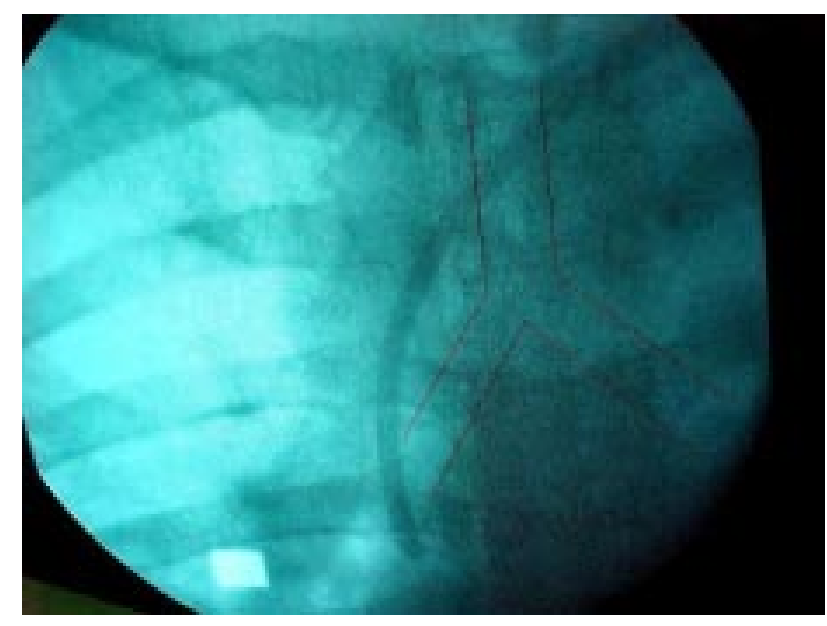

Figura 3 - Correto posicionamento na VCS. llustração da aferição fluoroscópica per-operatória através da distancia entre a ponta do cateter e a carina.

Já pelo lado esquerdo esta angulação não existe, permitindo uma queda suave para a VCS, o que facilita um correto posicionamento conforme podemos observar na Figura 4C.

Portanto mesmo nos mediastinos normais, podemos ter situações anatomias peculiares que dificultam um posicionamento correto exigindo do cirurgião o auxílio peri-operatório da fluoroscopia.

\section{2 - Tipos de vias de acesso}

Aos pontos de entrada de um CLP no sistema venoso chamamos de acesso, e eles podem ser obtidos através de 12 vias. Essas vias de acesso foram por nós classificadas segundo sua distância em relação ao mediastino em proximais e distais. São elas:

\section{a) Proximais}

1. Veia Jugular Interna direita (VJID)

2. Veia Jugular Interna esquerda (VJIE)

3. Veia Jugular Externa direita (VJED)

4. Veia Jugular Externa esquerda (VJEE)

5. Veia Subclávia direita (VSCD)

6. Veia Subclávia esquerda (VSCE)

7. Veia Cefálica direita (VCD)

8. Veia Cefálica esquerda (VCE)

\section{b) Distais:}

9. Veia Braquial direita (VBD)

10. Veia Braquial esquerda (VBE)

11. Veia Femoral direita (VFD)

12. Veia Femoral esquerda (VFE)

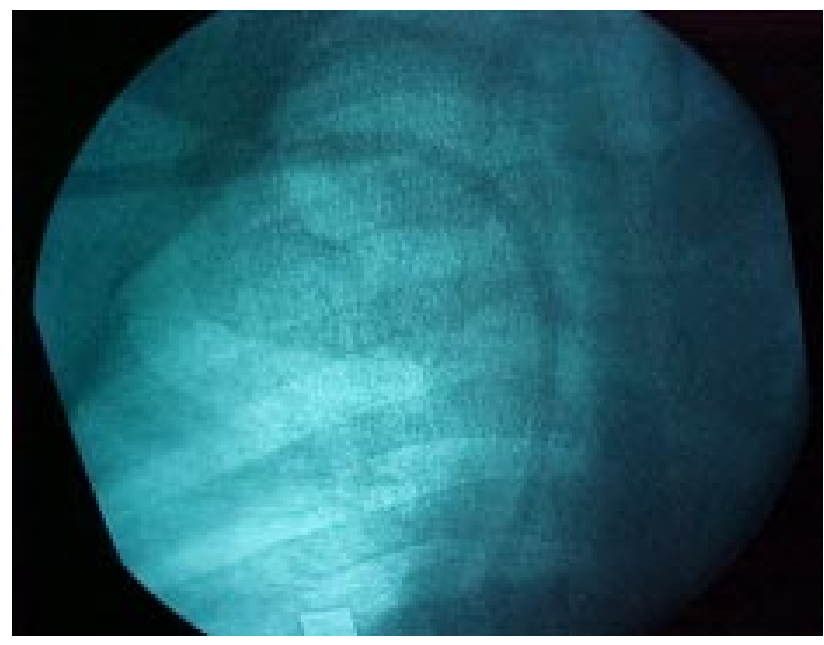

Figura 4 A - Fluoroscopia per-operatória mostrando a angulação que pode sofrer um cateter ao descer para a VCS quando o acesso é feito pela VSCD.

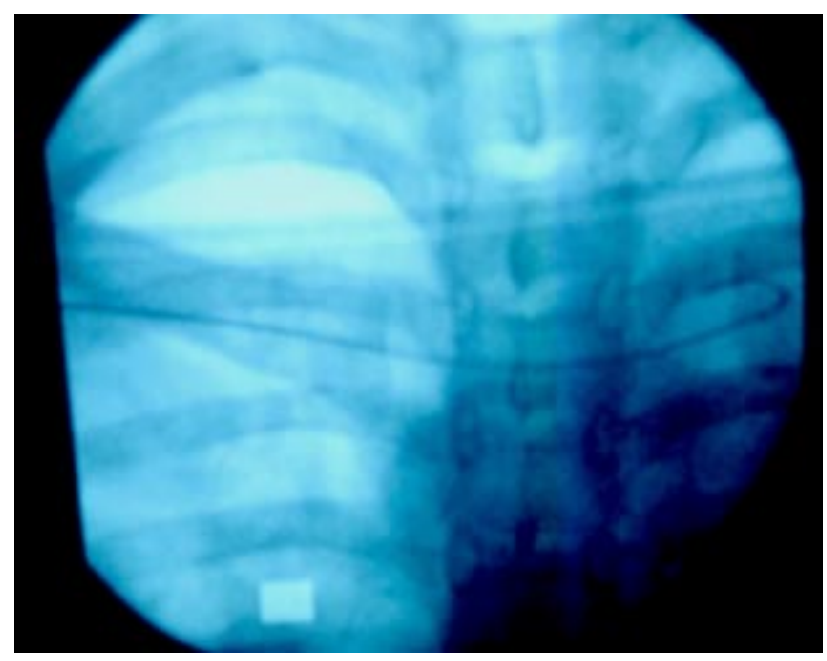

Figura 4 B - Fluoroscopia peri-operatória mostrando um acesso VSCD onde o guia cruzou o mediastino sem conseguir descer para a VCS.

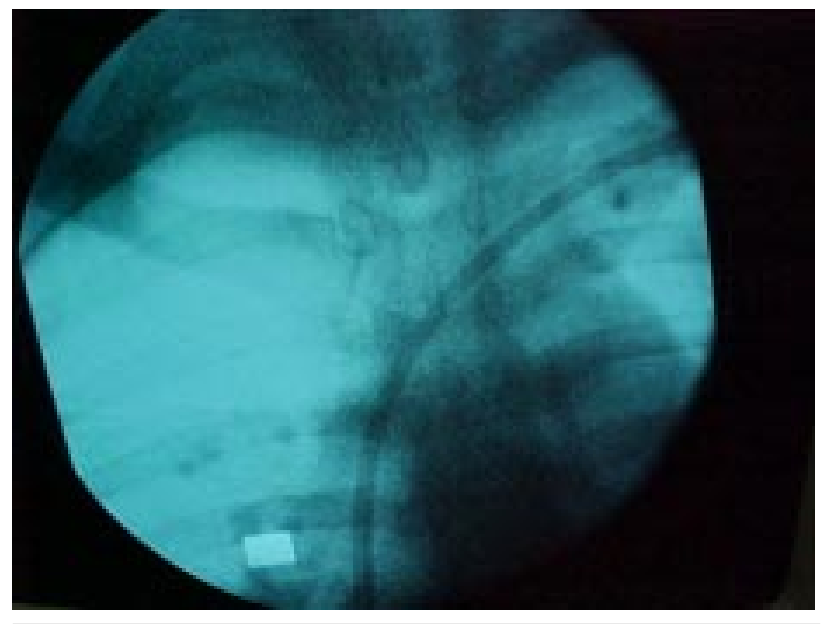

Figura 4 C- Acesso através VSCE tem um trajeto sem angulações, facilitando um posicionamento na VCS. 
Os acessos foram assim classificados em função de dois critérios básicos. Primeiro o de longa permanência, quando sabemos que quanto mais curto o segmento venoso do cateter menor o risco de agressão ao endotélio e, portanto, maior tempo de permanência. Em segundo lugar pela maior facilidade técnica para "instrumentar" a ponta do cateter, ou do fio-guia, para dirigi-lo até a VCS contornando alguma dificuldade de posicionamento, conforme mostrado acima.

Os acessos podem ser obtidos cirurgicamente por punção e/ou dissecção, cada qual com sua própria técnica. Os acessos são todos extra-mediastinais e, preferencialmente, utilizamos os proximais, que permitem ao cirurgião melhores condições técnicas de implante. Os distais são usados como exceção apesar de que, principalmente nas crianças, a exteriorização do cateter no braço é mais confortável e facilita os curativos.

As opções são muitas e a questão passa a ser qual delas seria a mais indicada para determinado paciente.

\section{3- Escolha da via de acesso}

A escolha correta de uma via de acesso influencia diretamente no tempo útil de um $\mathrm{CLP}^{7}$ e duas questões devem ser analisadas.

Primeiramente a de que o sucesso de um sistema de longa permanência só pode ser avaliado no longo prazo, quando ele efetivamente cumpriu seu objetivo, ou seja, pequenos detalhes que passam pela implantação cirúrgica, critérios de manipulação e quimioterapia utilizada, influenciam numa permanência prolongada. Num CTMO a permanência está em torno de 60 dias, porém quando ocorre doença enxerto contra hospedeiro $(\mathrm{DECH})$ na forma crônica, a necessidade do cateter em regime ambulatorial pode chegar a anos.

A segunda, especificamente cirúrgica, está no grau de dificuldade do implante, pois não são raras as más condições clínicas e hematológicas em pacientes candidatos a um TMO ou num pós-transplante imediato com $\mathrm{DECH}$, portanto poderemos estar diante de várias situações agravantes.

Alguns aspectos devem ser analisados para a escolha do melhor acesso naquele momento.

\subsection{1- Aspectos relacionados ao cateter}

Seria principalmente aquele relacionado ao comprimento do segmento intravascular.

Apesar do padrão de qualidade dos materiais atualmente utilizados na confecção destes sistemas ${ }^{8}$, o fato de mantermos algo sintético em contato permanente com o endotélio vascular sempre ocasiona algum grau de irritação que pode levar a sequielas inflamatórias e/ou trombóticas futuras com consequiências imprevisíveis ${ }^{9}$. Portanto quanto menor o segmento intravascular menor o contato com o endotélio, menor a probabilidade de tromboses e melhor o resultado final ${ }^{10}$.

$\mathrm{O}$ uso de um segmento longo, como ocorre nos acessos distais, deve ser considerado apenas pela impossibilidade de um acesso proximal. $\mathrm{O}$ acesso femoral por exemplo está indicado naqueles pacientes portadores de bloqueios de VCS, seja por tromboses, compressões ou patologia inflamatória, onde somente por um acesso inferior conseguimos alcançar a VCI.

Segmentos longos também aumentam a possibilidade de formação de coágulos no seu interior prejudicando sua funcionabilidade e reduzindo o tempo útil de permanência ${ }^{11}$.

\subsection{2- Aspectos relacionados à anatomia}

A complexão anatômica do tórax influi diretamente na escolha do acesso. Um arcabouço desfavorável pela conformação anatômica da clavícula (tipo exageradamente tortuosa ou reta) por exemplo, tem uma punção difícil e, se fizermos várias tentativas poderemos levar a punção pleural com conseqüente pneumotórax. É preciso saber o momento de buscar uma segunda opção de acesso.

O biótipo do paciente influencia diretamente na escolha do acesso na medida em que indivíduos obesos, com mais de $100 \mathrm{Kg}$, pescoço largo e curto, como vemos na Figura 5, são desafios ao cirurgião para optar por um acesso proximal que tenha um mínimo de agressividade e desconforto para o paciente.

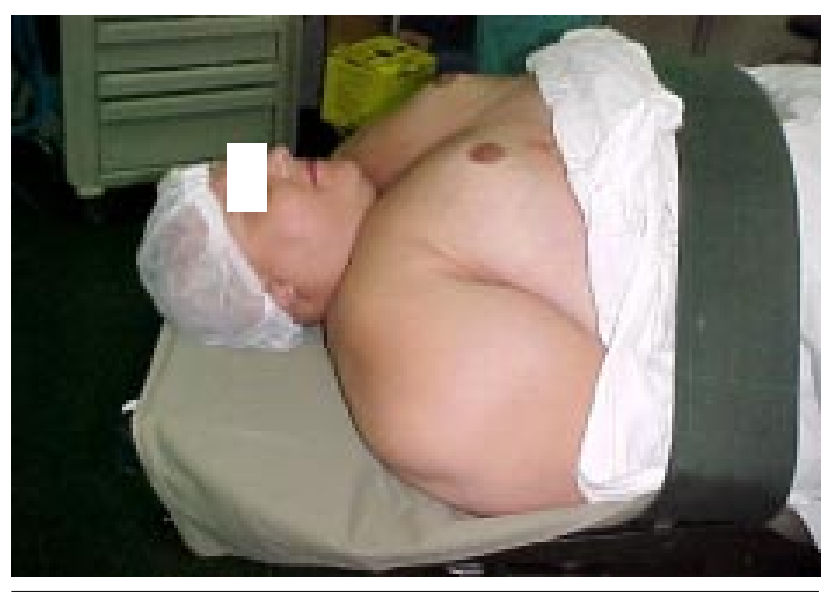

Figura 5 - Paciente obeso, abordagem difícil para acesso cérvicotorácico. 
As condições da pele na região cérvico-torácica, onde devemos atuar para a implantação de um cateter, também são relevantes na escolha do acesso pois poderá haver um comprometimento neoplásico que restrinja as opções. Uma cirurgia de implante não deve ser realizada numa área dérmica comprometida por doença (Figuras $6 \mathrm{~A}$ e B) onde a resistência a infecção é menor e que necessitará de curativos permanentes.
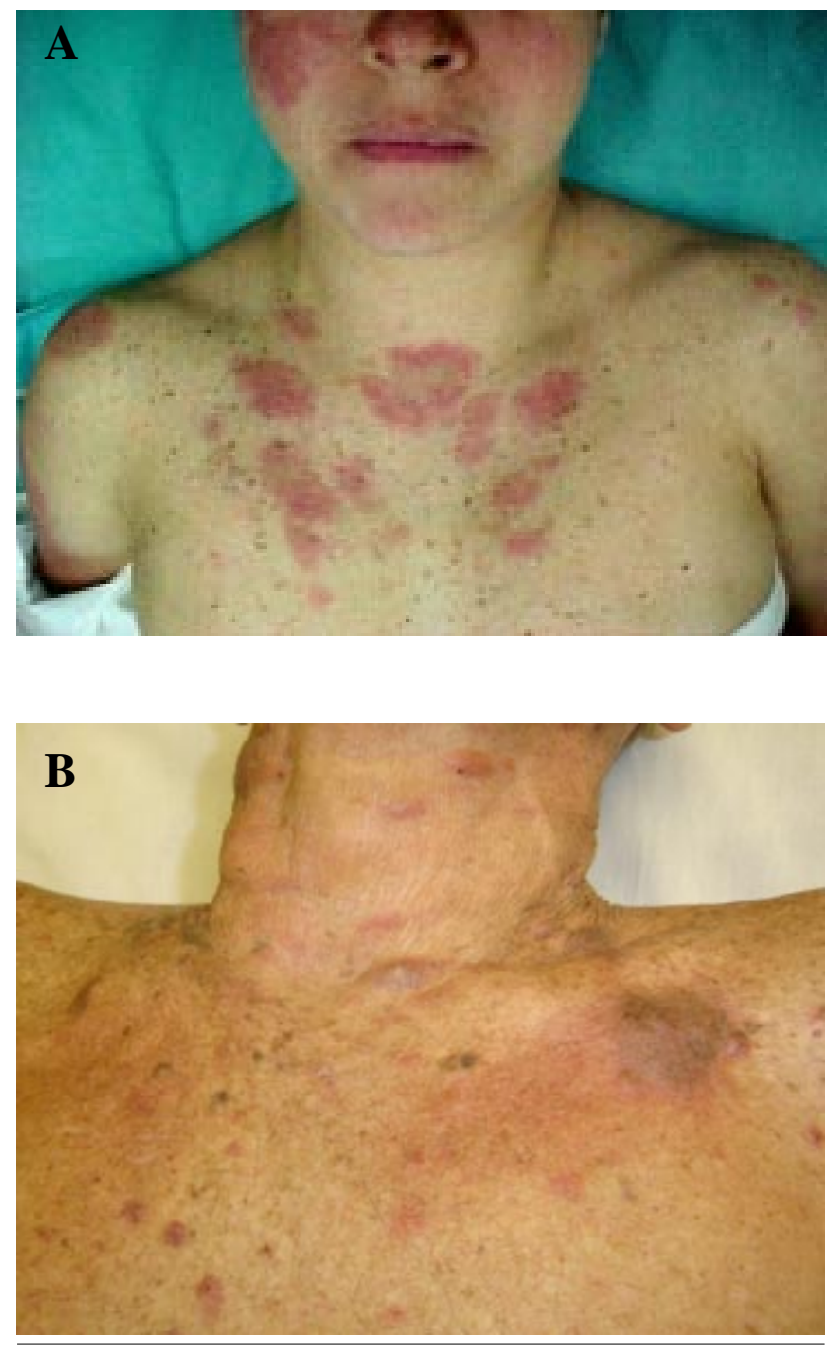

Figura 6 A e B - Infiltração leucêmica da pele comprometendo a área de implante.

Também nos TMO, não raramente o cirurgião se defronta com alterações dérmicas causadas pela $\mathrm{DECH}$, uma complicação pós-transplante grave, onde as condições da pele são totalmente adversas a qualquer procedimento cirúrgico. Entretanto, como a necessidade de um cateterismo é imperativa para a recuperação do paciente devemos procurar por um lo- cal menos comprometido, sabendo entretanto, da maior morbidade no uso do CLP pela facilidade de infecção na área operada (Figura 7).
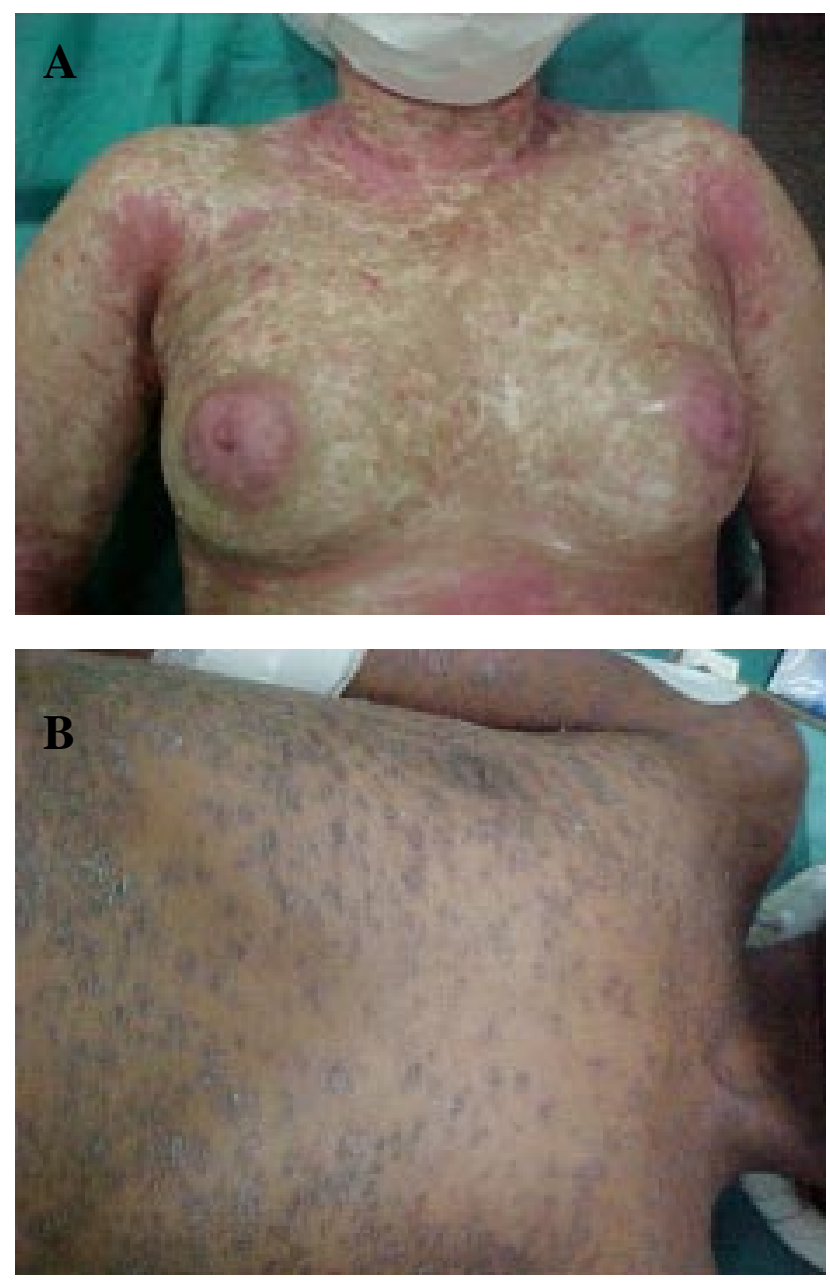

Figura $7 \mathrm{Ae} \mathrm{B}$-Comprometimento difuso de pele por DECH. Fase pós-transplante. Onde inserir um cateter?

Internamente, dentro do tórax, outras dificuldades podem ocorrer mas só poderão ser avaliadas durante a fluoroscopia, quando verificamos que não estamos conseguindo atingir a VCS. Estas dificuldades estão relacionadas principalmente aos desvios de trajeto por compressões ou tromboses dos grandes vasos.

Alguns pacientes, principalmente os portadores de linfomas, podem apresentar massas mediastinais que comprimem estes grandes vasos impedindo a progressão do cateter (Figura 8). Lesões cicatriciais e/ou retráteis, distorcem e angulam os troncos venosos desviando o cateter para regiões indesejáveis, provocando maus posicionamentos (Figura 9). História 
pregressa de trombose venosa ao nível dos ângulos braquiocefálicos, geralmente determinada por cateterismos anteriores, não são raros em pacientes já "politratados".

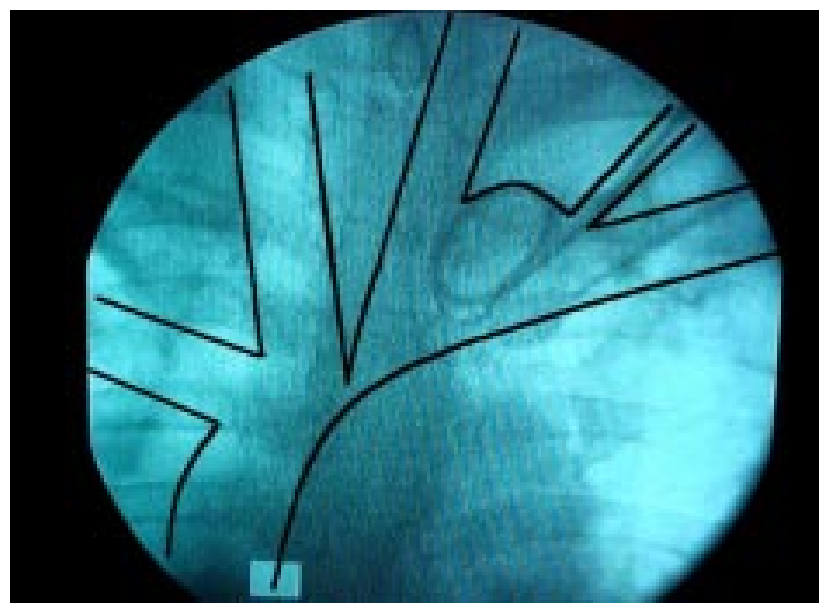

Figura 8 - Um acesso pelo lado esquerdo encontra obstrução total do tronco braquiocefálico esquerdo (ilustração sobre imagem fluoroscópica). A tentativa de posicionamento chegou a enrolar o guia metálico introduzido através de um acesso VJEE sem obter progressão devido à presença de compressão mediastinal ou trombo.

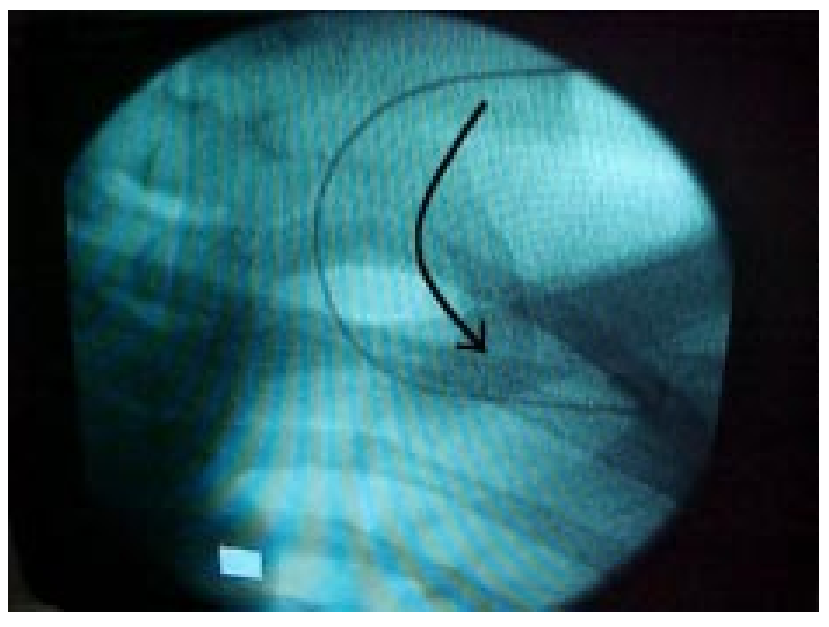

Figura 9-Acesso VJIE com desvio do guia metálico para a VSCE devido a alguma alteração no tronco braquiocefálico esquerdo que impediu a progressão para a VCS.

\section{6- TÉCNICAS DE IMPLANTAÇÃO}

Consideramos 6 vias de acesso para implantação de um CLP, cada qual com sua própria técnica e indicação ${ }^{12,13}$. Neste capítulo entretanto vamos mostrar em detalhes apenas o acesso VJI, numa técnica que chamamos de combinada (dissecção + punção). Motivados estamos em descreve-la pelo fato de que é uma técnica segura e atua como última opção em casos considerados difíceis.

Para o jovem cirurgião, o domínio da técnica de acesso VJI é fundamental, pois lhe credita a certeza de que o paciente sairá da S.O com seu cateter implantado seja qual for o grau de dificuldade que esteja diante dele. É um acesso por dissecção tecidual onde existem referências anatômicas que são visualizadas e afastadas num processo cirúrgico convencional até chegar à VJI, quando então será possível avalia-la e punciona-la por visão direta. Todas as demais técnicas são de execução mais fácil.

Numa experiência própria, analisada em 1684 cateterismos realizados no INCA, tive 2 pacientes que saíram da S.O sem o cateter implantado devido à impossibilidade técnica de posiciona-lo na VCS; havia bloqueio mediastinal superior e inferior sendo necessário, primeiramente, colocar um stent.

\section{1- Equipamento de sala de cirurgia}

Um Fluoroscópico do tipo arco é imprescindível para realização da cirurgia. Exames hemodinâmicos per-operatórios, como já dissemos, são fundamentais devido a freqüente ocorrência de maus posicionamentos. Em nossa experiência cerca de $30 \%$ dos casos apresentaram algum tipo de alteração mediastínica que necessitou do auxílio fluoroscópico para conduzir o cateter para a VCS.

O cirurgião e demais auxiliares que atuam na sala de cirurgia devem portar os coletes protetores de irradiação sob o capote cirúrgico.

\section{2- Posição na mesa de cirurgia e anestesia}

Os acessos proximais, escolhidos de rotina, são realizados sempre sobre a região cervical (supraclaviculares) e torácica (infraclaviculares), à direita ou esquerda, e que devem ser convenientemente expostas para o ato operatório.

Numa posição anatômica, em hiper extensão do pescoço e membros superiores em adução (Figura 10), expomos amplamente a face anterior do pescoço para acessos cervicais, e a parede anterior do tórax e sulco delto-peitoral para acessos infraclaviculares. Nesta posição podemos atuar sobre 4 vias de acesso de cada lado, aumentando as opções de ação cirúrgica sem mobilizar o paciente. A colocação de um outro campo, sob a mandíbula, isola completamente a área cirúrgica sem dificultar a respiração e a visão do paciente, dando a ele maior conforto numa cirurgia sob anestesia local (Figura 11). 


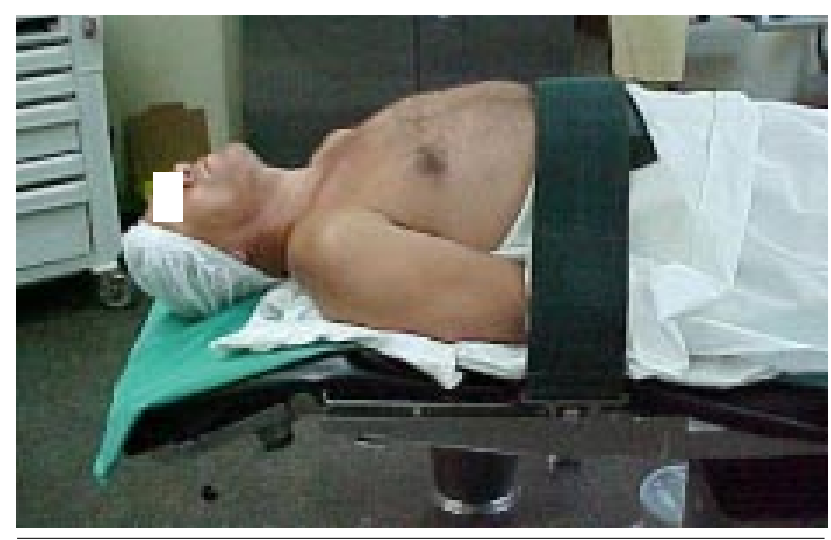

Figura 10 - Posição correta do paciente na mesa operatória. Exposição da região cérvico-torácica anterior permitindo acesso pela direita ou esquerda.

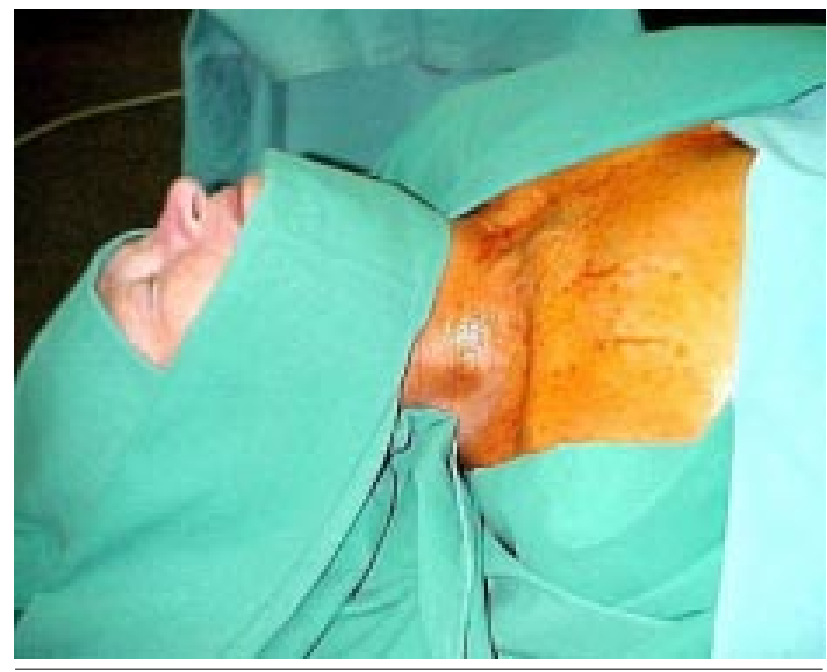

Figura 11 - Exposição da área operatória com vias aéreas e campo visual completamente livre e expondo uma área operatória que permite atuar sobre as 4 vias de acesso proximais sem modificar a posição do paciente.

A anestesia utilizada em adultos é a local com xilocaína a $1 \%$, sem adrenalina. Em crianças e préadolescentes entretanto, é necessária a anestesia geral, uma vez que não teremos o controle psicológico do paciente em se manter imóvel e calmo por cerca de 20 a 40 minutos, mas que pode levar 2:00 $\mathrm{h}$ em casos difíceis.

\section{3 - Tipo de CLP indicado para os TMO}

Os pacientes candidatos a um TMO devem portar sempre o cateter do tipo semi-implantável, duplo lúmen de diâmetros iguais, chamado cateter de Hickman ${ }^{14}$. O diâmetro padrão para os adultos é de 9,6 Fr e para as crianças geralmente $7 \mathrm{Fr}$.

Nos casos de transplante autólogo se pode utilizar um cateter mais calibroso, com cerca de
12 a 14 Fr, para permitir a aférese de sangue periférico e, na sequiência, o TMO.

\section{4- Instrumental cirúrgico específico para téc- nica Seldinger}

Atualmente é possível realizar um acesso venoso por 2 métodos. Por punção ou por dissecção.

A técnica por punção, conhecida como técnica Seldinger ${ }^{15}$, é realizada com o auxílio de um "Kit Introdutor" (Figura 12 A) que normalmente acompanha o cateter e é composto por:

1) Uma agulha de punção de $7 \mathrm{~cm}$ de comprimento e 18 gauge.

2) Um guia metálico tipo "J", flexível, de $50 \mathrm{~cm}$ de comprimento e $0,96 \mathrm{~mm}$ de diâmetro.

3) Um Introdutor, cujo diâmetro depende do diâmetro do cateter a ser utilizado (nos adultos $10 \mathrm{Fr}$ ).

4) Um Dilatador.

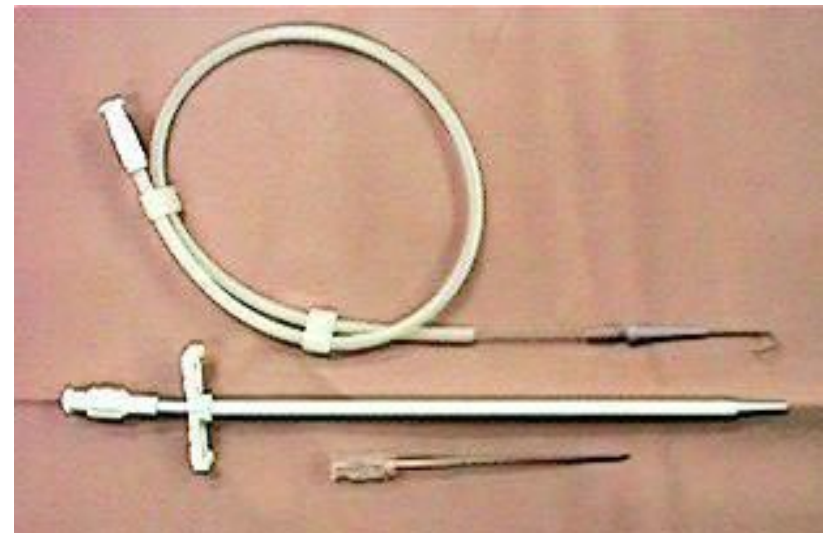

Figura $12 \mathrm{~A}$ - Kit introdutor: de cima para baixo, o fio-guia tipo "J", conjunto introdutor/dilatador e agulha de punção.

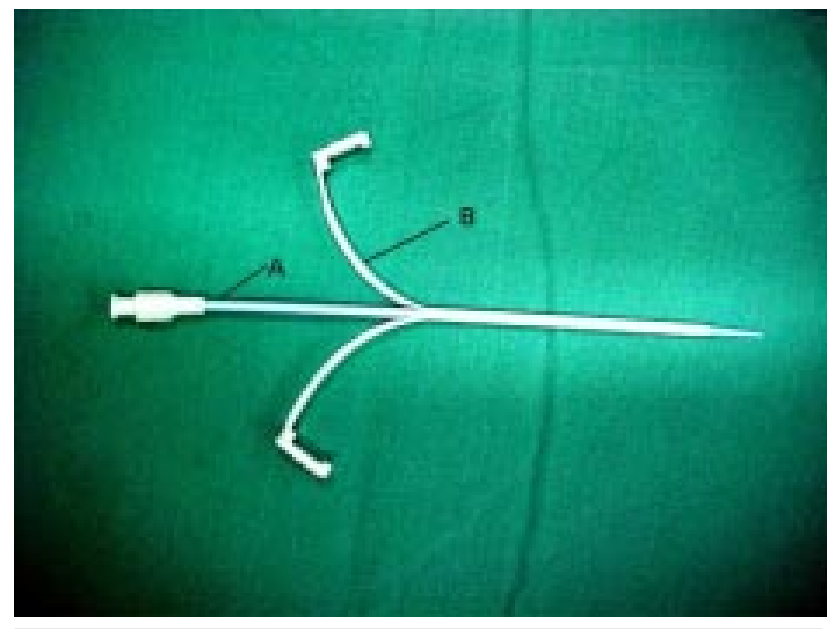

Figura 12 B - Aspecto do introdutor (B), também chamado de "camisa", em posição semi-aberta "vestindo" o dilatador (A). 
O conjunto Fio-guia/Dilatador/Introdutor trabalha como uma peça composta (uma por dentro da outra). O fio-guia tem a função de impedir falsos trajetos, orientando a introdução venosa do componente Dilatador/Introdutor.

O Dilatador, que leva consigo o Introdutor, tem a função de abrir o caminho de maneira atraumática até o interior do vaso. Após o posicionamento dessas 3 peças, em conjunto dentro do vaso, retiramos as 2 mais internas (o fio-guia e o Dilatador) mantendo apenas o Introdutor por onde introduzimos o cateter, conforme veremos ilustrado adiante .

O Introdutor é uma peça plástica, semi-rígida composta por duas faces côncavas "soldadas" fragilmente para formar um tubo. Assim, para retirá-lo após a introdução do cateter, basta "quebrá-lo" longitudinalmente em toda sua extensão, separando-o em duas faces semicirculares iguais (Figura $12 \mathrm{~B}$ ).

\section{5- Técnicas de implantação por acessos supra- claviculares}

Os acessos supraclaviculares são feitos através das veias jugulares, interna (VJI) e externa (VJE), sendo abordadas tanto pelo lado direito como esquerdo.

O acesso VJE é obtido sempre por dissecção. O VJI permite dissecção, punção ou forma combinada, isto é, quando a punção é feita sob visão direta do vaso dissecado. No CEMO os acessos cervicais são utilizados como segunda opção. Os acessos infraclaviculares têm nossa preferência por serem mais rápidos e permitirem túneis subcutâneos mais curtos reduzindo os riscos de hematomas em pacientes plaquetopênicos.

\subsection{1- Veia jugular externa (VJE)}

A VJE é o acesso tecnicamente mais fácil.

Descrita inicialmente por Wool ${ }^{16} \mathrm{em} 1983$, ela tem se mostrado uma técnica segura, com baixo índice de morbidade por ser tratar apenas de uma dissecção venosa superficial. Devido a isto, é o acesso de melhor opção para pacientes graves, apesar de que, nem sempre é passível de execução, e só poderá ser obtida se ela for visível na região cervical inferior, próxima à clavícula. Se o cirurgião não puder visualizala não será possível executar este acesso.

É uma técnica que também depende muito da fluoroscopia, pois seu trajeto tortuoso pode desviar o cateter para veia jugular anterior ou leva-lo para o braço num sentido contrário através da veia subclávia.

Tecnicamente se trata de uma dissecção venosa clássica, com ligadura distal do vaso e reparo em laço, proximal. A flebotomia é feita entre esses 2 pon- tos e o cateter introduzido no sentido crânio-caudal em direção ao mediastino. Posteriormente ele é fixado ao vaso através da ligadura do laço de reparo (proximal), comprimindo a parede do vaso contra o cateter, impedindo o extravasamento sanguíneo.

A incisão cirúrgica correta para este acesso é feita na região cervical lateral, sobre a base do triângulo supraclavicular, mais próximo possível à clavícula (Figura 13A, A), nunca na região alta do pescoço (Figura 13A, B). A incisão baixa permite um cateter mais curto, um túnel subcutâneo menor e, principalmente, um "ângulo de retorno" mais aberto, evitando dobras que possam reduzir o fluxo/refluxo do sistema.

$\mathrm{O}$ ângulo de retorno de um cateter é aquele formado pela inversão de sentido sofrida pelo cateter ao penetrar no vaso. Uma vez que ele é exteriorizado na região torácica anterior necessita ascender pelo subcutâneo e adquirir um sentido descendente após penetrar no vaso. A formação deste ângulo, que pode chegar a $360^{\circ}$ deve ser suave para permitir o livre fluxo do sistema, sem estreitamentos ou acotovelamentos da luz do cateter (Figura 13 B).

\subsection{2- Veia jugular interna (VJI)}

Os acessos jugulares internos são os mais complexos, por isso os mais mórbidos sob o ponto de vista técnico, e o domínio de sua técnica, como já dissemos, é fundamental. O trajeto curto e retilíneo proporcionado pelo acesso VJID faz dele a última e melhor opção de sucesso para os casos difíceis. Também numa emergência, quando não podemos contar com o auxílio da fluoroscopia per-operatória esta técnica deve

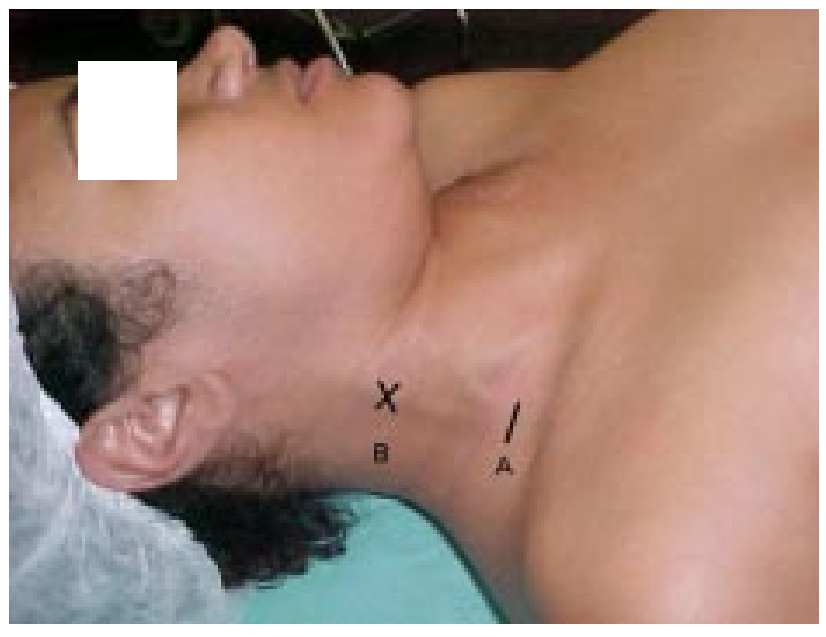

Figura 13 A - VJED visível, apta para dissecção. Em "A" temos o local correto para incisão cirúrgica, sobre o triângulo anatômico supra-clavicular e próximo à clavícula. Em "B", o local impróprio para a incisão. 


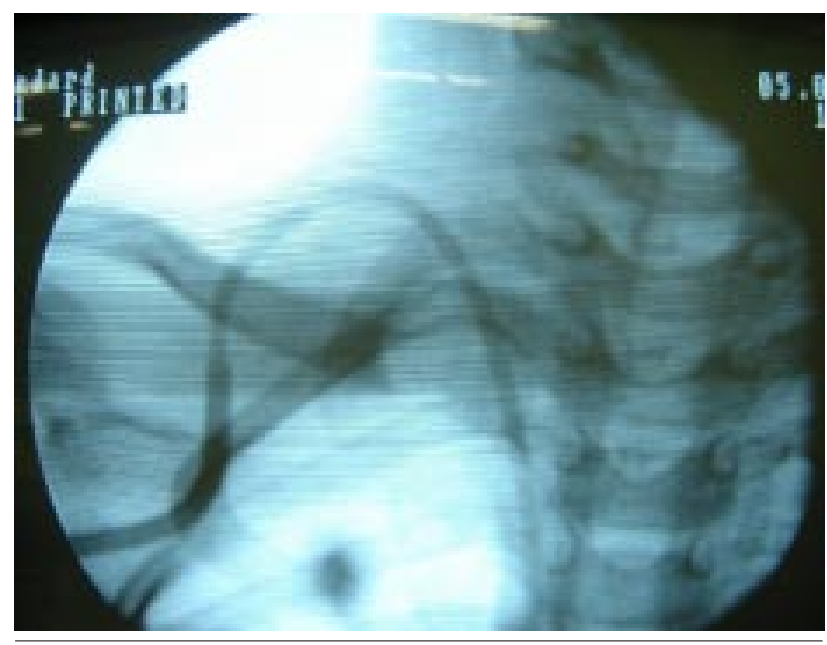

Figura 13 B - Cateter ascendente pelo subcutâneo inverte o sentido ao penetrar no sistema venoso. Observar que o ângulo de retorno está bem alargado, sem "acotovelamento", permitindo o livre fluxo e refluxo.

ser escolhida pela maior probabilidade de sucesso no posicionamento. É a última opção quando as demais já não obtiveram sucesso.

A dificuldade técnica encontrada na execução do acesso VJI se reforça na medida em que está indicada principalmente para situações clínicas e/ou anatômicas adversas. São, por exemplo, os pacientes obesos com mais de $100 \mathrm{Kg}$ com acesso subclávio difícil, e os outros acessos inviáveis. São aqueles pacientes com graves distúrbios de coagulação, com trombose de ângulo venoso, com radioterapia mediastínica, com formações expansivas intratorácicas e desvios complexos de trajeto.

Os acessos VJI podem ser obtidos por 3 técnicas: punção simples ${ }^{17}$, dissecção $o^{18}$ ou por uma associação das duas primeiras chamada por nós de técnica combinada.

Quando indicado um acesso VJI, preferimos a técnica combinada, onde a punção venosa feita sob visão direta evitando acidentes hemorrágicos que possam comprometer o tratamento. A punção simples, mesmo em mãos experientes, tem risco de hematomas por punção inadvertida de carótida. Também consideramos, que para um CLP, devemos evitar punções na região alta do pescoço pelos motivos já descritos, o que nos leva a necessidade de uma punção jugular baixa, próximo a clavícula, com uma direção cerca de $45^{\prime}$ graus em relação a traquéia; é portanto uma punção problemática.

Considerando que uma experiência com 1.000 tentativas de punção VJI em pacientes portadores de coagulopatias foi descrita por Goldfarb ${ }^{17}$ em 1982 e que a técnica do acesso VJI por dissecção, por nós descrita em $1986^{18}$, só citando 2 autores, são procedimentos a muito executado, preconizamos e aconselhamos a técnica combinada para situações difíceis.

Passamos a descrever a técnica combinada para o acesso VJI.

\section{$1^{0}$ Tempo: Dissecção, visualização e punção da VJI}

Iniciamos o ato operatório com uma incisão dérmica transversa com cerca de $3 \mathrm{~cm}$ de comprimento na região cervical anterior, sobre o bordo interno do músculo esternocleidomastoideo (ECM) e a cerca de $3 \mathrm{~cm}$ acima da clavícula.

Progredimos a dissecção em profundidade incisando o músculo cuticular do pescoço e visualizando o bordo interno do músculo ECM, que representa a principal referência anatômica para atingir os vasos profundos do pescoço. Seja qual for a conformação anatômica do pescoço o cirurgião deve localizar este músculo para direcionar a dissecção.

A partir daí prosseguimos rebatendo o músculo ECM gradativamente para fora, com auxílio de um afastador de Farabeuf, até a visualização do músculo omohioideo $(\mathrm{OH})$ que cruza esta região num sentido oblíquo. Ao afastar o $\mathrm{OH}$ para cima com o mesmo afastador, obteremos pela região infra-omohioidea a visualização da VJI. A punção é feita por contra-abertura na região cervical lateral e sob visão direta através da dissecção realizada (Figura 14).

Uma vez puncionada, introduzimos o fio-guia por dentro da agulha direcionando-o para a VCS e logo a seguir retiramos a agulha, deixando apenas o guia posicionado (Figura 15). Neste momento estudamos por fluoroscopia o trajeto venoso obtido. Como podemos observar na Figura 16 o trajeto percorrido é curto e sem angulações quando acessado pela VJID.

Conferido por fluoroscopia o trajeto percorrido pelo fio-guia, inicia-se o tempo cirúrgico da passagem do cateter propriamente dito.

\section{$2^{\circ}$ Tempo: Posicionamento do cateter}

Primeiramente a escolha do local da exteriorização do cateter SI (óstio do cateter) na região torácica anterior, cerca de 6 a $8 \mathrm{~cm}$ abaixo da linha hemiclavicular. Uma pequena incisão é feita na pele e um túnel subcutâneo é confeccionado interligando o óstio ao ponto de punção. Preferimos os túneis curtos a fim de reduzira formação de hematomas. Túneis longos não influenciam no resultado final do uso de um CLP, portanto não são vantajosos. 


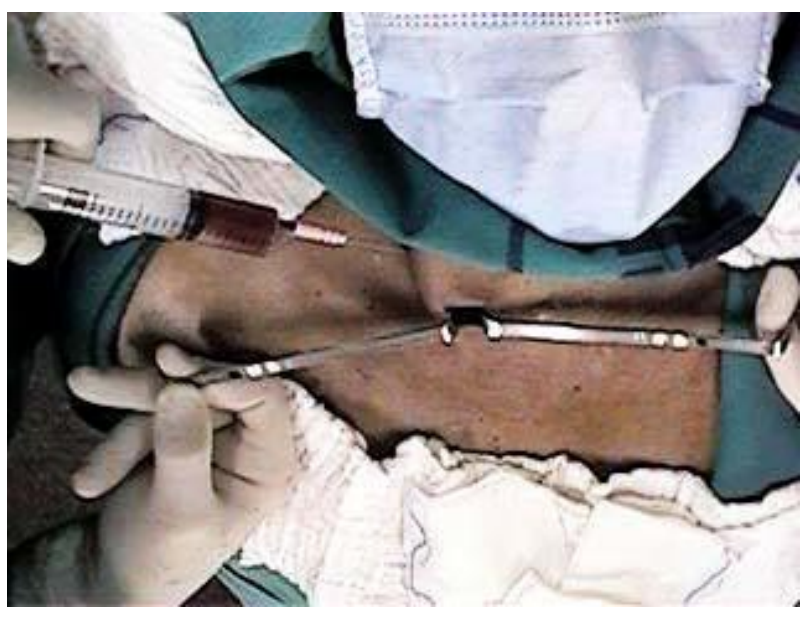

Figura 14 - Punção quase perpendicular da VJID por contraabertura. A visão do vaso é feita através da incisão cervical anterior, entre os dois afastadores de Farabeuf.

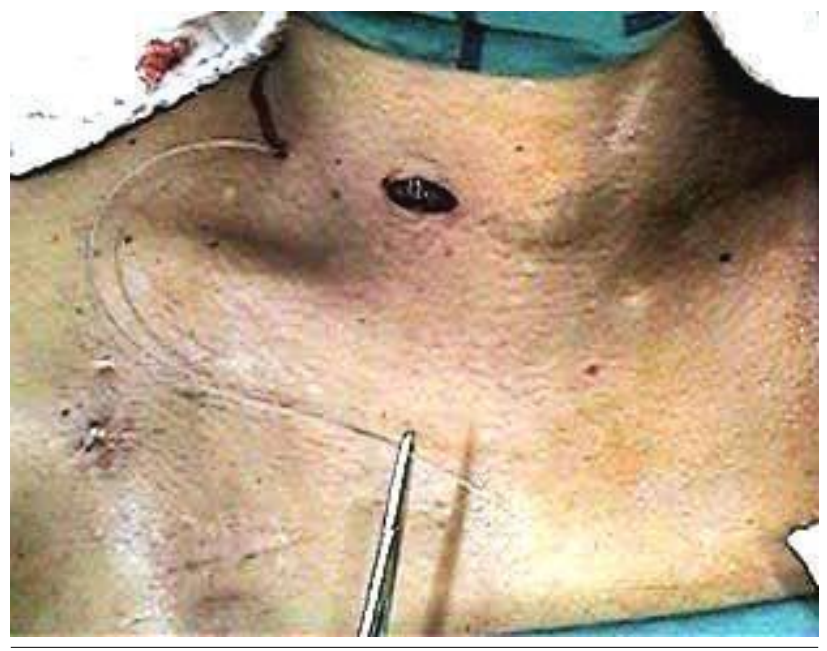

Figura 15 - Fio-guia introduzido no mediastino através da punção lateral da VJID.

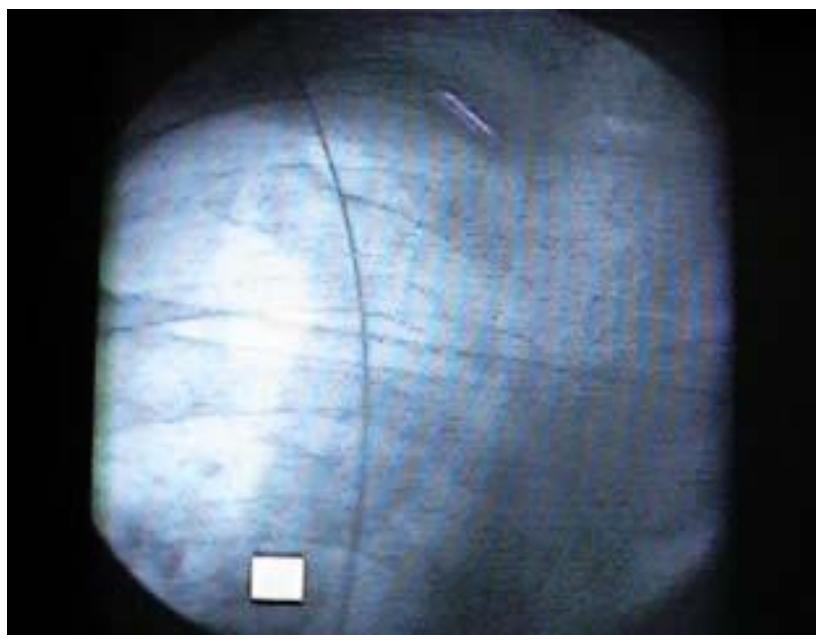

Figura 16 - Fluoroscopia per-operatória confirmando o correto posicionamento do fio-guia introduzido através da VJID em direção a VCS. Segmento endovenoso curto e retilíneo.
A transposição do cateter pelo túnel subcutâneo é uma manobra que pode ser feita com os instrumentos que acompanham o Kit Introdutor ou até mesmo com pinças hemostáticas. Nós preferimos uma manobra menos traumática, pois são pacientes sujeitos a sangramentos, e para tal utilizamos um fio inabsorvível $\mathrm{n}^{\circ} 0$ transpassado por dentro da agulha da punção (Figura 17A). Esta montagem é conduzida através do subcutâneo unindo os 2 pontos (Figura 17B). A agulha é retirada e o fio mantido no subcutâneo. A seguir confeccionamos uma alça na extremidade distal do fio e com ele laçamos a ponta do cateter que, dobrado sob si mesmo, é então tracionado através do túnel até o ponto da punção onde se encontra o fioguia (Figura $17 \mathrm{C}$ ).

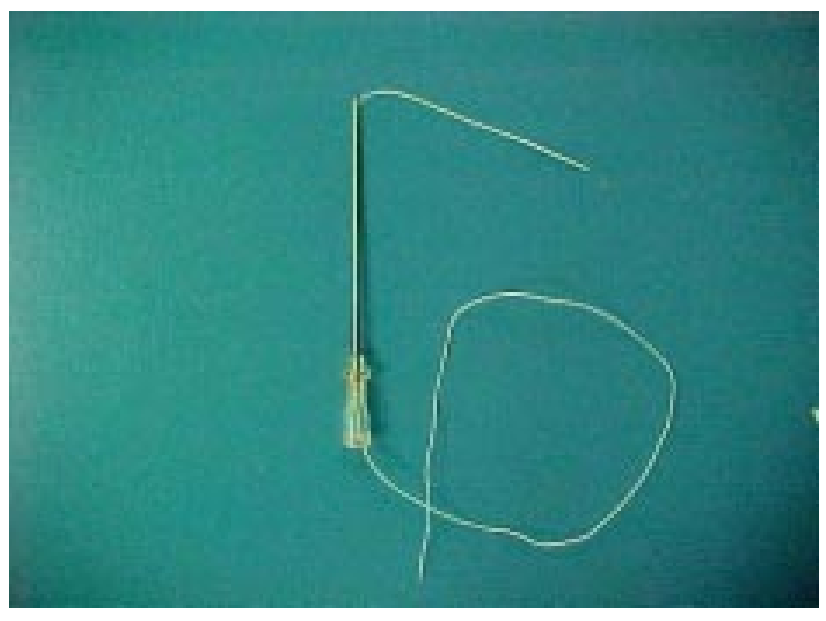

Figura 17 A- Idéia de um "Transpassador de subcutâneo", que produz um mínimo de trauma ao criar o túnel subcutâneo por onde passará o cateter.

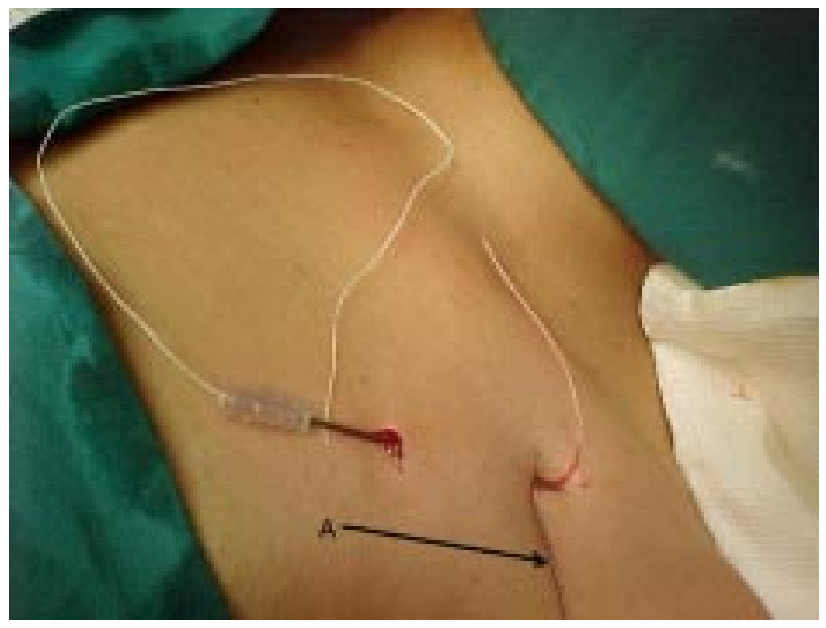

Figura 17 B - Um exemplo de confecção de túnel subcutâneo (ilustrando um acesso VSCE). Momento em que o transpassador une os 2 pontos. A "seta A" mostra o fio-guia previamente posicionado na VSCE. 


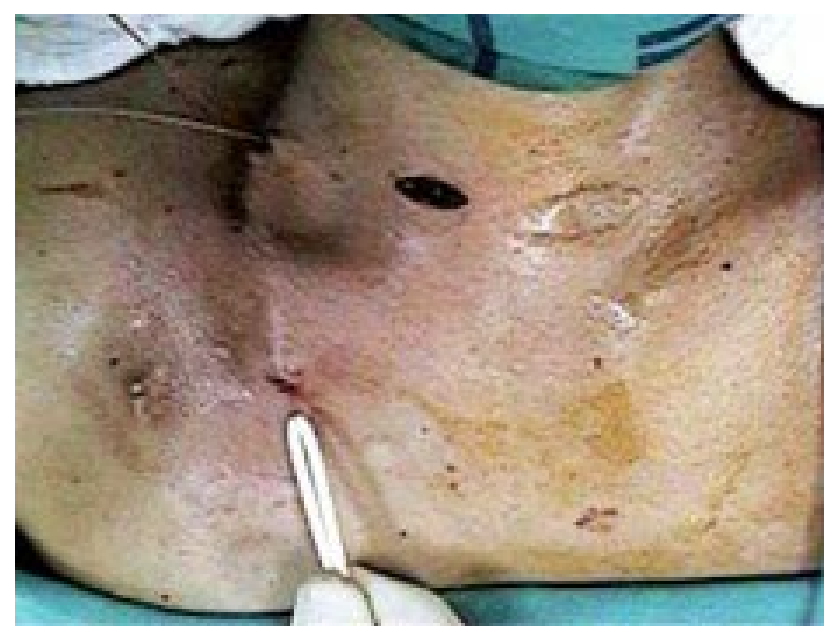

Figura $17 \mathrm{C}-\mathrm{A}$ extremidade proximal do cateter é dobrada sobre si mesma e passado por dentro de um laço feito num fio $\mathrm{n}^{\circ} 0$.

Neste momento o cateter é seccionado e acomodado na posição natural sem trações ou retrações (Figura 18). O “cuff” de Dracon®deve ser acomodado a cerca de $2 \mathrm{~cm}$ para dentro do óstio de exteriorização, conforme mostrado na Figura 1-A.

O "cuff" próximo ao óstio impede que, com a movimentação natural do paciente, ocorra uma fricção constante (entra e sai) do cateter no subcutâneo, provocando trauma e subseqüente infecção local ${ }^{19}$.

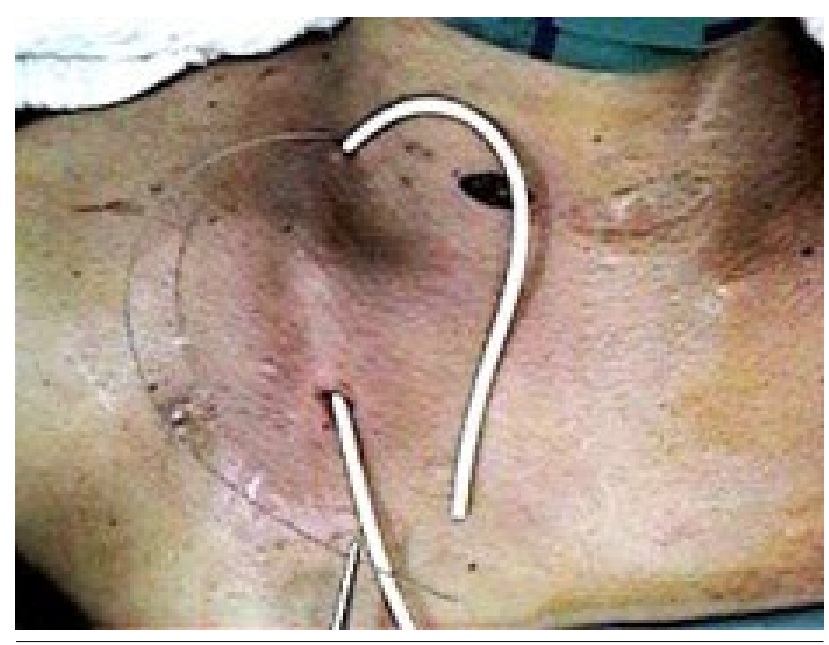

Figura 18 - Manobra de passagem do cateter pelo túnel subcutâneo completado, unindo o óstio do cateter ao ponto de punção, onde se encontra o fio-guia. O cateter acomodado no subcutâneo deve ser cortado no comprimento desejado para alcançar a VCS.

\section{$3^{\circ}$ Tempo: Posicionamento endovascular do cateter}

Iniciamos agora o tempo de introdução do cateter no sistema venoso. O conjunto dilatador/introdutor "veste" o fio-guia penetrando na pele, por pulsão, até o interior do vaso sanguíneo. Após posicionar o conjunto parcialmente dentro da luz do vaso abrimos o introdutor longitudinalmente até a pele (Figura 19) e retiramos o dilatador com o fio-guia, para então introduzirmos o cateter no sistema venoso por dentro do introdutor (Figura 20).

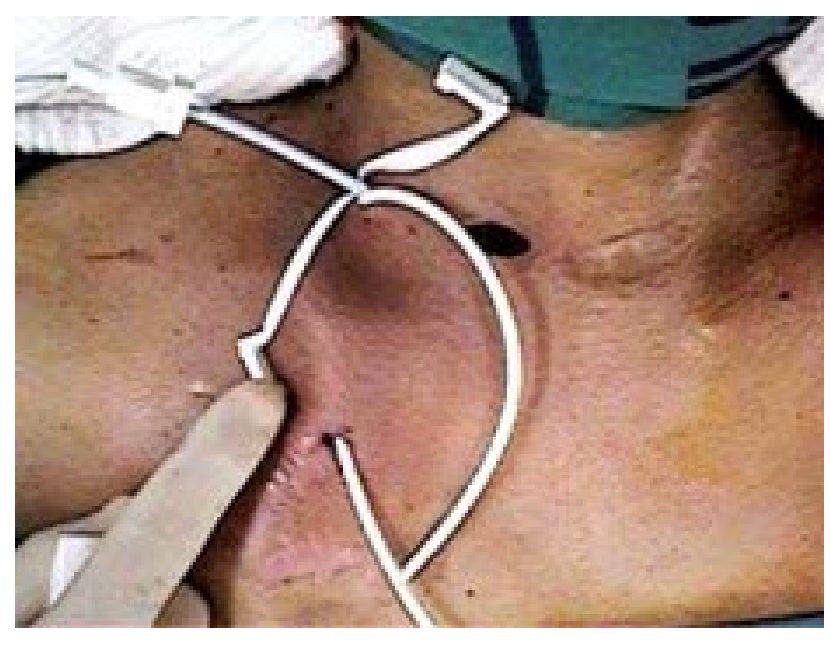

Figura 19-Introdução do "conjunto Introdutor/Dilatador" através do fio-guia. Vemos o Introdutor já aberto longitudinalmente e o dilatador com o fio-guia sendo retirados para introdução do cateter.

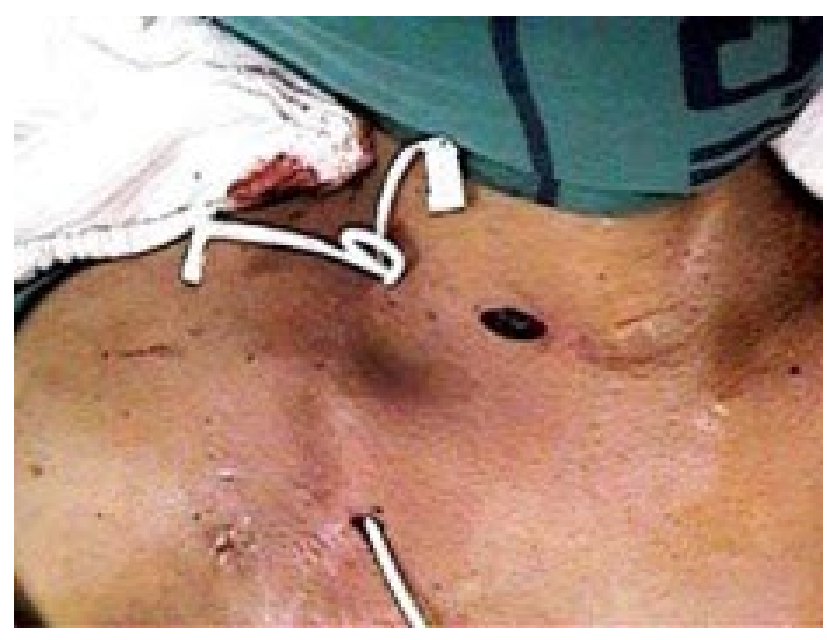

Figura $20-0$ cateter penetrando no sistema venoso profundo através do Introdutor, que será retirado abrindo-o longitudinalmente em duas faces semi-circulares.

Ao passar o cateter, sem retirar ainda o introdutor, novo estudo fluoroscópico deve ser feito para conferir seu posicionamento, pois talvez seja necessária manobra de correção. Constatado o correto posicionamento poderemos retirar o introdutor (Figura 21). 


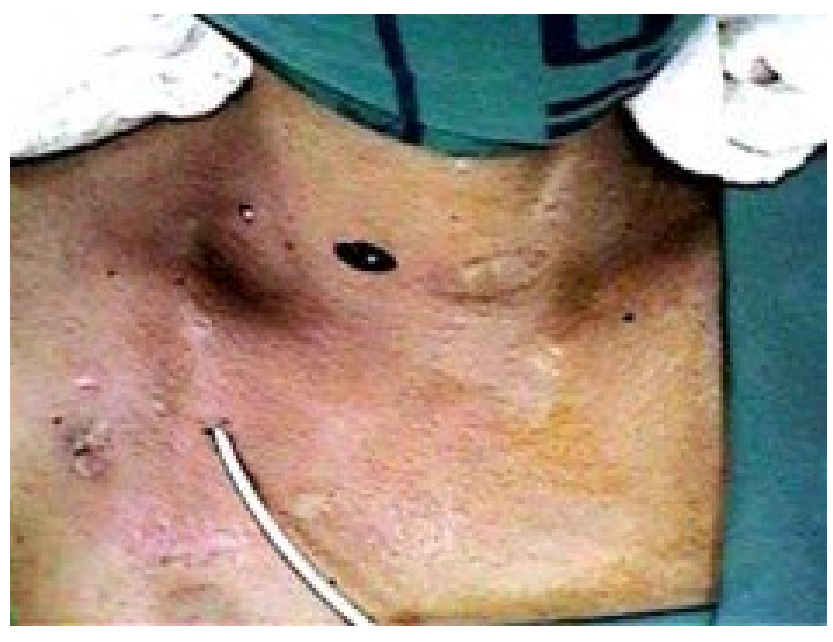

Figura 21 - Aspecto final, mostrando o óstio de exteriorização na região infraclavicular direita, uma mínima ferida lateralmente na região cervical, por onde o cateter penetra no vaso saguíneo, e uma incisão na região cervical anterior. O ângulo de retorno do cateter é bem aberto, sem acotovelamento.

\section{$4^{\circ}$ Tempo: Fixação do sistema}

A fixação definitiva do sistema ocorre, de maneira consistente, somente 3 semanas após, sofrendo um processo que chamamos de "maturação". Ela é promovida por uma reação inflamatória, e posteriormente fibrosa, da gordura subcutânea aderindo firmemente o "cuff" de Dacron ${ }^{\circledR}$. Esta fixação idealizada por Broviac ${ }^{1}$ quando bem adaptada no longo prazo, promove uma completa integração do cateter à pele, conforme vemos na Figura 22.

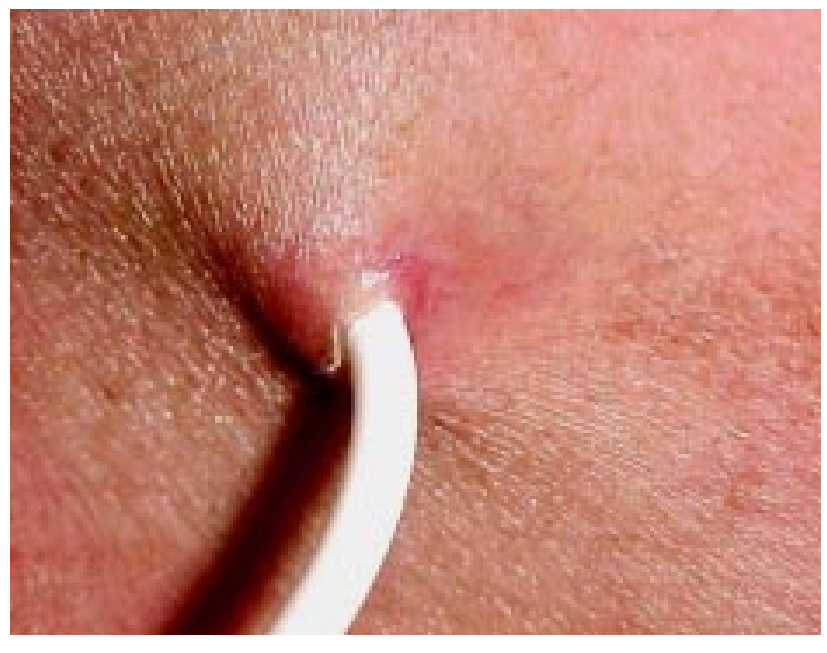

Figura 22 - Maturação tardia do óstio de exteriorização do cateter mostra a perfeita adaptação entre a borracha de silicone e o corpo humano.

\subsection{3- Veia subclávia (VSC)}

Os acessos subclávios ${ }^{20}$ fazem parte das técnicas operatórias proximais infraclaviculares, e por terem vários aspectos positivos têm a nossa preferência como primeira opção.

Nos aspectos positivos podemos enumerar:

1) Rápida execução com mínimo de sofrimento

2) Túnel subcutâneo mais curto em relação aos cervicais

3) Segmento endovascular curto. Menor trauma, maior permanência

4) Sem problemas relacionados ao ângulo de retorno

5) Melhor resultado estético

Por ser uma técnica obtida exclusivamente por punção, entretanto, alguns fatores influenciam no sucesso destes cateterismos. Uma complexão torácica anatomicamente desfavorável ou em vigência de plaquetopenia severa, a morbidade desta técnica deve ser considerada.

A questão maior que vemos na sua execução é quando estamos diante de plaquetopenia severa. No Quadro 1 observamos que $18.5 \%$ dos acessos VSC realizados foram feitos em condições plaquetopênicas abaixo de $40.000 / \mathrm{mm}^{3}$, e não observamos complicação. Portanto, em mãos experientes, a punções de VSC em vigência de plaquetopenia severa pode ser feita quando escolhida criteriosamente.

\subsection{4- Veia cefálica (VC)}

Os acessos cefálicos ${ }^{21}$ podem ser considerados como a segunda opção se não obtivermos êxito num acesso VSC. Ela é feita mediante uma incisão com cerca de 3 a $4 \mathrm{~cm}$ de comprimento sobre o sulco delto-peitoral, logo abaixo da clavícula, caminhando até o plano muscular e dissecando-a entre os bordos do músculo peitoral, internamente, e do músculo deltóide, externamente. A este nível a VC encontrase praticamente afluindo para a VSC. É importante dizer que a VC nem sempre se encontra viável para um cateterismo, principalmente quando o membro superior já recebeu vários ciclos de quimioterapia.

\subsection{5- Veia braquial e femural (VB e VF)}

São acessos distais considerados por nós como indicação de exceção, pois produzem segmentos endovasculares longos, indesejáveis, que aumentam a superfície de contato do silicone com o endotélio e que podem obstruir por coagulo. Enquanto os catete- 
res implantados por acessos proximais têm cerca de 15 a $20 \mathrm{~cm}$ de comprimento endovenoso, os distais têm $40 \mathrm{~cm}$ no acesso VB e $90 \mathrm{~cm}$ no acesso VF. Também a maior distância entre o ponto da punção e a VCS dificulta manobras de correção de posicionamento da ponta do cateter quando necessárias.

Os femurais, especialmente, são acessos indicados quando existe um processo obstrutivo a nível supracardíaco causado por compressões, desvios de mediastino ou tromboses venosas. São situações onde somente através de um acesso inferior é possível alcançar a região cava, posicionando o CLP na veia cava inferior (VCI).

$\mathrm{O}$ acesso VF é obtido na região crural e pode ser feito por dissecção da veia safena ou por punção direta a este nível. Nos casos de punção a técnica utilizada é a mesma já descrita, utilizando-se o "Kit introdutor".

Os onco-hematologistas se queixam muito das dificuldades de manutenção dos óstios posicionados na face anterior da coxa devido os freqüentes quadros de diarréia que ocorrem durante o TMO e que podem induzir a contaminação do CLP.

\section{7- RESULTADOS}

Apresentamos a análise de 524 cateterismos de longa permanência realizados CEMO-INCA, RJ, no período de setembro de 1997 a dezembro de 2002, ou seja, 64 meses. Todos os cateteres foram implantados no período pré, per ou pós-transplante. O tempo médio de permanência de um CLP para um TMO foi de 60 dias.

As principais patologias submetidas à implantação de um CLP para realização do TMO foram:

1) Leucemias em 200 casos, $38 \%$.

2) Anemia Aplásica Severa (AAS) em 43 casos, $8 \%$.

3) Linfomas em 130 casos, $25 \%$

4) Mieloma Múltiplo em 59 casos, $12 \%$

5) Miscelânea em 92 casos, $17 \%$.

Durante o período, cerca de $20 \%$ dos cateteres implantados apresentaram algum tipo de complicação que necessitaram sua substituição, dos quais $15 \%$ dos pacientes necessitaram de 2 implantações, $4 \%$ de 3 implantações e $1 \%$ de 4 ou 5 implantações.

Quanto ao grau de dificuldade cirúrgica, a plaquetopenia foi o principal fator complicador. 11,64\% dos pacientes apresentavam menos de 10.000 plaquetas $/ \mathrm{mm}^{3}, 19,84 \%$ entre 10 e 40.000 e $68,5 \%$ acima de 40.000 plaquetas $/ \mathrm{mm}^{3}$ (Quadro 1).

Estes dados são importantes porque influenciam diretamente na escolha da via de acesso. Com um risco de sangramento iminente devemos avaliar as condições clínicas e anatômicas para optar pelo acesso menos arriscado. A situação clínica mais crítica para a realização da cirurgia esteve no pós-transplante imediato, quando cerca de $36 \%$ dos pacientes apresentavam menos de 10.000 plaquetas $/ \mathrm{mm}^{3}$ (Quadro 1).

Quadro 1 - Vias de acessos utilizadas em relação ao número de plaquetas.

\begin{tabular}{|c|c|c|c|c|c|c|c|c|c|}
\hline \multirow{2}{*}{$\begin{array}{l}\text { Vias de acesso } \\
\text { VSC }\end{array}$} & \multicolumn{2}{|c|}{$\begin{array}{l}\text { PLAQUETAS } \\
<10.000 \mathrm{~mm}^{3}\end{array}$} & \multicolumn{3}{|c|}{$\begin{array}{l}\text { PLAQUETAS } \\
>10.000 \\
40.000 \mathrm{~mm}^{3} \\
\end{array}$} & \multicolumn{2}{|c|}{$\begin{array}{c}\text { PLAQUETAS } \\
<>40.000 \mathrm{~mm}^{3}\end{array}$} & \multicolumn{2}{|c|}{$\begin{array}{c}\text { TOTAL } \\
\text { por acesso }\end{array}$} \\
\hline & 11 & - $\quad 4,5 \%$ & 34 & - & $14 \%$ & 197 & - $\quad 81,5 \%$ & 242 & $-46 \%$ \\
\hline VJE & 28 & $-\quad 18,5 \%$ & 41 & - & $26 \%$ & 88 & $56 \%$ & 157 & $-30 \%$ \\
\hline VJI & 7 & - $\quad 10,5 \%$ & 12 & - & $18 \%$ & 48 & $-\quad 71,5 \%$ & 67 & $-13 \%$ \\
\hline VC & 3 & $-\quad 25 \%$ & 0 & - & $0 \%$ & 9 & $75 \%$ & 12 & $2 \%$ \\
\hline VB & 12 & - $\quad 33,3 \%$ & 15 & - & $41,7 \%$ & 9 & $25 \%$ & 36 & $7 \%$ \\
\hline VF & 0 & $0 \%$ & 2 & - & $20 \%$ & 8 & $80 \%$ & 10 & $2 \%$ \\
\hline $\begin{array}{c}\text { TOTAL } \\
\text { por plaquetas }\end{array}$ & 61 & $-11,64 \%$ & 104 & 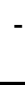 & $19,84 \%$ & 359 & $-68,52 \%$ & 524 & $-100 \%$ \\
\hline
\end{tabular}


Com relação às melhores opções na escolha dos acessos, o Quadro 1 demonstra que o acesso VSC foi o mais executado no CEMO, em $46 \%$ dos casos.

$\mathrm{O}$ acesso VJI, mais mórbido e como tal escolhido para situações complexas, foi necessário em 67 (13\%) pacientes do CEMO, dos quais 10,5\% com uma plaquetopenia inferior a $10.000 / \mathrm{mm}^{3}$, demonstrando pela freqüência elevada que o cirurgião deve estar apto a realizar este acesso em condições clínicas adversas ${ }^{5}$.

O acesso VB também apresentou uma incidência elevada de escolha quando as condições hematológicas são mais graves. Observamos que $75 \%$ dos acessos VB foram feitos com uma plaquetopenia abaixo de $40.000 / \mathrm{mm}^{3}$.

\section{8- COMPLICAÇÕES}

Complicações existem e devem ser conhecidas para serem evitadas ${ }^{7,22,23}$. Didaticamente podemos dividi-las em de curto e longo prazo.

No curto prazo podem ocorrer 4 tipos de problemas relacionados ao ato operatório: 1) hematoma, 2) pneumotórax, 3) mau posicionamento e 4) infecção de ferida cirúrgica.

No médio e longo prazo temos: 5) infecção sistêmica, 6) trombose venosa profunda (TVP) e deiscência ou abortamento do cuff de fixação do cateter SI.

\section{1- Hematomas}

Os hematomas são ocasionados por punção arterial inadvertida ou durante a confecção do túnel subcutâneo, motivo pelo qual não preconizamos túneis longos para estes pacientes. A punção inadvertida da artéria carótida é mais grave do que a da subclávia devido a sua localização e maior possibilidade de adquirir grandes proporções, o que levaria inclusive ao adiamento do TMO.

O hematoma, quando ocorre, também pode sofrer contaminação no período da aplasia medular, evoluir para sepsis e necessitar substituição do cateter, muitas vezes num momento crítico do TMO.

\section{2 - Pneumotorax}

O surgimento de pneumotórax, por demais conhecido nas tentativas de punção de subclávia, depende diretamente da experiência do cirurgião mas, se ocorrer, deve ser prontamente diagnosticado e tratado. Na nossa experiência, no CEMO, esta complicação não ocorreu e creditamos isto à escolha criteriosa dos acessos, onde não insistimos na técnica quando a punção se mostra difícil.

\section{3 - Mau posicionamento}

Os maus posicionamentos não são $\operatorname{raros}^{24}$, e até ocorrem com certa freqüência quando existe comprometimento tumoral ou radioterápico do mediastino ocasionando desvios e compressões dos grandes vasos. Também podem ocorrer devido a fenômenos trombóticos prévios onde o cateter não consegue progredir, sendo necessário mudar o sentido do seu trajeto (vertical ou horizontal) ou o lado do acesso para obter êxito.

Recomendamos sempre o uso de fluoroscopia peri-operatória para estudar a anatomia mediastínica, avaliando e corrigindo eventuais direcionamentos anômalos.

Alguns autores consideram que o posicionamento da ponta do cateter na porção alta da VCS, próximo ao ângulo braquiocefálico direito, é um fator de risco independente e significativo para o desenvolvimento de trombose venosa no médio e longo $\operatorname{prazo}^{25,26}$.

\section{4 - Infecção de parede}

As celulites quando se formam no túnel subcutâneo, principalmente em pacientes no período de aplasia medular, são determinantes para substituição do sistema quando se instala uma sepsis.

No médio e longo prazo as situações complicadoras são:

\section{5 - Infecção sistêmica (sepsis)}

Diante de um quadro séptico, com hemoculturas positivas colhidas através do CLP, nem sempre significa que o foco desencadeante seja o cateter. Muitas vezes o fator etiológico está em outro sítio que, por translocação, coloniza o cateter de forma refratária precipitando sua retirada. Em situações de colonização bacteriana é possível manter um sistema tratando-o com antibióticos administrados através do próprio CLP, porém nas infecções por fungos é aconselhável a sua retirada. 


\section{6 - Trombose venosa profunda (TVP)}

TVP é uma complicação grave e relativamente freqüente. Alguns estudos avaliando cateterismos venosos profundos com ultrassonografia e Doppler, encontraram cerca de $33 \%$ de trombose num estudo com pacientes em $\mathrm{UTI}^{27}$. Outros autores, em Departamentos de Oncologia, têm relatado uma freqüência de $8 \%{ }^{28}$. Na análise de 428 CLP retirados no INCA, observamos que $4 \%$ deles foram motivados por TVP.

Mais recentemente, com a difusão dos CLPs, alguns autores têm procurado explicar as modificações sofridas pelo endotélio venoso quando em contato prolongado com o silicone e que seriam responsáveis pelo desencadeamento da trombos ${ }^{9,29}$. Entre elas a ação traumática, constante, estimularia um processo hiperplásico da íntima do vaso, com conseqüente adesividade plaquetária e formação progressiva de uma lâmina de fibrina em torno do cateter levando a sua obstrução por trombose.

Outros aspectos que também atuariam no longo prazo estimulando a formação de trombos seriam: A qualidade do material, a ação irritante de certos quimioterápicos principalmente em pacientes com história de quimioterapia de longa data, o posicionamento incorreto da ponta do cateter, a técnica cirúrgica utilizada, o poli cateterismo, a radioterapia prévia do mediastino e o número de plaquetas. Todos influenciam diretamente, evidenciando que a patogenia da TVP, em pacientes portadores de CLP, é multifatorial ${ }^{3,8,9,30}$.

A TVP pode ocorrer agudamente ou de forma insidiosa e gradativa durante o curso de utilização de um CLP. Quando aguda, ela surge abruptamente, provocando dor, algumas vezes febre, circulação colateral e edema do pescoço ou do braço segundo o lado ou o acesso venoso que estiver em uso. Quando insidiosa, é caracterizada por uma queda progressiva no rendimento do cateter, reduzindo inicialmente o refluxo e posteriormente, de forma gradativa, também o seu fluxo até a obstrução completa ${ }^{9,30}$.

Esta seqüência é típica da formação da lâmina de fibrina que vai se formando na parede do grande vaso, incorporando o segmento distal do CLP até bloquear seu funcionamento, conforme imagem radiológica mostrada na Figura 23.

Alguns autores, na tentativa de minimizar esta complicação, preconizam esquemas profiláticos com utilização de doses baixas de anticoagulantes ou terapêuticas, desobstrutivas com uso de fibrinolíticos ativadores do plasminogênio tecidual recombinante, tipo
Alterplase (rt-PA) e Tenecteplase (TNK) ou mesmo a estreptoquinase $(\mathrm{sk})^{31,32,33}$.

\section{7 - Obstrução do cateter}

Como pudemos verificar acima, as obstruções ocorrem em decorrência de complicações fora do cateter. As obstruções ocorridas pela formação de trombos no interior do cateter são geralmente ocasionadas por uma manutenção ou manipulação mal conduzida. Lavagens periódicas com soluções heparinizadas devem ser feitas mensalmente num ambulatório especializado quando o uso do CLP não for constante. Durante o TMO, as heparinizações não são necessárias, pois o CLP está em contínuo funcionamento.

\section{8 - Deiscência com exteriorização do cuff}

Como vimos, o cuff de Dacron® idealizado por Broviac $^{1}$ tem por finalidade fixar o cateter no longo prazo sem a necessidade do clássico ponto de sutura. Entretanto, quando este processo de maturação não ocorre devidamente, o cuff pode se exteriorizar (abortamento) e, sem fixação, permitir que o cateter saia espontaneamente.

Dois fatores são diretamente responsáveis: 1) Quando o cuff é posicionado muito próximo da pele, principalmente em obesos, forçando um abortamento.

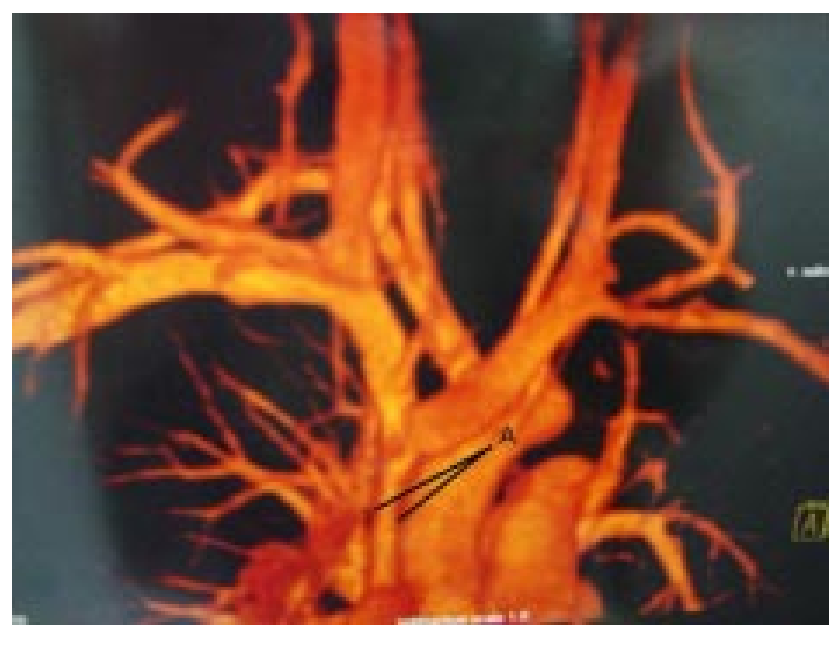

Figura 23 -Angio-ressonância mostrando uma VCS com aspecto retrátil e espessamento da parede em toda sua extensão provocado por lâmina de fibrina (detalhe A). Observa-se também a presença de trombo ao nível do ângulo venoso braquiocefálico direito. O paciente portava CLP prévio e uso prolongado de quimioterapia. Foi necessário sua retirada por impossibilidade de refluxo e redução significativa do fluxo. 
Geralmente ocorre tardiamente, ou 2) quando ocorre infecção localizada no túnel subcutâneo. Neste caso o abortamento é precoce.

\section{9- CONCLUSÕES}

O cirurgião envolvido com um CTMO tem a responsabilidade de comandar as implantações dos CLPs e deve cumprir tecnicamente com os princípios básicos de uma implantação de longa permanência.

Estes princípios são creditados a:

1. Menor comprimento do segmento endovascular do cateter visando diminuir a área de contato com o endotélio. Isto pode ser obtido utilizando os acessos proximais,

2. Correto posicionamento da ponta do cateter na VCS. Posicionamentos altos acarretam no longo prazo a formação de tromboses.

3. Uma correta escolha da via de acesso, considerando aspectos clínicos e anatômicos que facilitem o processo de implantação contornando obstáculos que eventualmente podem ocorrer durante o posicionamento na VCS.

4. Opção por acesso preferencialmente proximal a fim de cumprir o item 1 e permitir um posicionamento com mínimo trauma ao endotélio, pois eventualmente haverá necessidade de instrumentar o cateter para vencer os obstáculos de trajeto e alcançar a VCS.
Nos pacientes submetidos a TMO o índice de sucesso no uso de um CLP é menor do que nos pacientes submetidos à quimioterapia convencional, tendo em vista que a aplasia medular com conseqüente déficit imunológico predispõe a infecções e elas podem comprometer os cateteres.

No CEMO-INCA cerca de $20 \%$ dos pacientes necessitaram substituir o sistema numa fase crítica do transplante obrigando o cirurgião a executar uma nova implantação em condições clínicas desfavoráveis.

Assim, achamos conveniente ressaltar que nossa visão tática considera sempre, principalmente nos transplantes halogenêicos, a necessidade de "guardar" uma segunda opção de acesso, que seja de fácil execução, de baixa morbidade, e que possa ser utilizada numa situação de momento adverso durante o desenrolar do TMO. Sem um acesso venoso profundo não se pode instituir o tratamento clínico, por isto o implante de um CLP é um procedimento sem contraindicação. Pode ser feito a qualquer momento em qualquer situação clínica.

Concluímos dizendo que a visão do cirurgião diante de pacientes hematológicos deve ser sempre preventiva de complicações, buscando soluções técnicas de baixa morbidade, alta objetividade e facilidade de execução, oferecendo ao onco-hematologista um acesso venoso confiável que suporte um tratamento quimioterápico agressivo como é o TMO.

Pires e Albuquerque M. Surgery of Long-Term Catheters (LTC) in a Bone Marrow Transplantation Center. Medicina (Ribeirão Preto) 2005; 38 (2): 125-142.

ABSTRACT: The chapter discourse about the use of Long-Term Catheters (LTC) in a Bone Marrow Transplantation Center (BMTC), approaching surgical aspects with purpose to prepare surgeons to face critical hematological patients, whether in prepare of a BMT or in complex situations during or after the transplant.

Established in a 2.000 procedures carry out by the author at the National Cancer Institute $(\mathrm{NCl})$ is empathized, in didactic narrative to young surgeons, to give the guide of surgical practice necessary to the success of these catheters placement in BMTC.

There are discussed features of the LTC by him self, like types and models, the convenient indication for each one, the usual technical approach to be adopted (including wide description of the Internal jugular vein access), the difficult situations with outstanding issues of the mediastinum anatomy pitfalls and the ways to by-pass it, and finally, the results and complications followed by the use of these systems specifically in patients of a BMTC.

KEYWORDS: Catheterization, Central Venous. Surgery. Long-Term Central Venous Catheter. Cancer Chemotherapy. Bone Marrow Transplantation. Neoplasms. 


\section{REFERÊNCIAS BIBLIOGRÁFICAS}

1 - Broviac JW, Cole JJ, Scribner BH. A Silicone rubber atrial catheter for prolonged parenteral alimentation. Surg Gynecol Obstet 1973;136:602-6.

2 - Pires e Albuquerque M, Theóphilo FJ, Saraiva JA, Preira AF. Cateteres valvulados em oncologia: Nova opção para vias de acesso prolongadas. Rev Col Bras Cirurg 1988; 15(3): 218-22.

3 - Habal MB. The biologic basis for the clinical application of the silicones. Arch. Surg 1984; 119: 843-8.

4 - Juno RJ, Knott AW, Racadio J, Warner BW. Reoperative venous access. Semin Pediatr Surg 2003; 12: 132-9.

5 - Doerfler ME, Kaufman B, Goldenberg AS. Central venous catheter placement in patients with disorders of hemostasis. Chest 1996; 110:185-8.

6 - Testut L, Jacob O. Tratado de anatomia topográfica, $8^{\underline{a}}$ ed. Barcelona: Salvat;1997.

7 - Henriques HF, Karmy-Jones R, Knoll SM, Copes WS, Giordano JM. Avoiding complication of long-term venous access. Am J Surg 1993;59:555-8.

8 - Braley S. The chemistry and properties of medical grade silicone rubber. J Macromol Sci Chem 1970;23:529.

9 - Verso M, Agnelli G. Venous thrombolism associated with long-term use of central venous catheters in cancer patients. J Clin Oncol 2003; 21 (19): 3665-75.

10 - Kuriakose P, Colon-Otero G, Paz-Fumagalli R. Risk of deep venous trombosis associated with chest versus arm central venous subcutaneous port catheters: a 5-year singleinstitution. J Vasc Interv Radiol 2002;13(2 Pt 1):179-84

11 - Baier RE, Dutton RC. Initial events in interaction of blood with a foreign surface. J Biomed Matter Res 1969; 3: 191-206.

12 - Goldfarb P, Coldwell D. Chronic venous access bedside placement technique and complications. Cancer Pract 1994; 2: $279-83$.

13 - Nelson EW. Venous access techniques. Urol Clin North Am 1986;13:475-87.

14 - Hickman RO, Buckner CD, Cliff RA, Sanders JE, Stewart P, Thomas ED. A modified right atrial transplant recipients. Surg Gynecol Obstet 1979;148:871-5.

15 - Seldinger FA. Catheter placement of the needle in percutaneous radiography. Acta Radiol 1953; 39:368-76

16 - Wool NL, Straus AK, Roseman DL. Hickman catheter placement simplified. Am J Surg 1983; 145: 283-4.

17 - Goldfarb G, Lebrec D, Percutaneous cannulation of the internal jugular vein in patients with coagulopathies: an experience based on 1.000 attemps. Anesthesiology 1982; $56: 321-3$

18 - Pires e Albuquerque M, Theóphilo F. Cateter valvulado para tratamento quimioterápico: Técnica de implantação. Rev Col Bras Cirurg 1986; 13(4): 141-4.
19 - Flowers RH, Schwenzer KJ, Kopel RF, Fisch MT, Tucker SI, Farr BM. Efficacy of an attachable subcutaneous cuff for the prevention of intravascular catheter-related infection. JAMA 1989;261:878-83.

20 - Kirkemo A, Johnston MR. Percutaneous subclavian vein placement of Hickmancatheter. Surgery 1982;91:349-51.

21 - Povoski SP. A prospective analysis of the cephalic vein cutdown approach for chronic indwelling central venous access in 100 consecutive cancer patients. Ann Surg Oncol 2000; 7:496-502.

22 - Ballard JL, Bunt TJ, Malone JM. Major complications of angioaccess surgery. Am J Surg 1992;164:229-32.

23 - Schwarz RE, Coit DG, Groeger JS. Transcutaneously tunneled central venous lines in cancer patients: an analysis of device-related morbidity factors based on prospective data collection. Ann Surg Oncol 2000; 7:441-9.

24 - Dierks M, Whitman E. Catheter tip placement in the analysis of central venous access device outcome. J Vasc Access Devices 1995;1:11-4.

25 - Mayo DJ. Fibrin sheath formation and chemotherapy extravasation: a case report. Support Care Cancer 1998; 6: 51-6

26 - Puel V, Caudry M, Metayer P, Baste JC, Midy D, Marsault C, Demeaux H, Maire JP. Superior vena cava trombosis related to catéter malposition in cancer chemotherapy given through implanted ports. Cancer 1993;72:2248-52

27 - McGEE DC, Gould MK. Preventing complications of central venous catheterization. N Engl J Med 2003;348:1123-33

28 - Lemmers NW, Gels ME, Sleijfer DT, Plukker JT, van der Graaf WT, de Langen ZJ, Droste JH, Koops HS, Hoekstra HJ. Complications of venous access ports in 132 patients with disseminated testicular cancer treated with polychemotherapy. J Clin Oncol 1996;14:2916-22

29 - Xiang DZ, Verbeken EK, Van Lommel AT, Stas De M, de Weyen L. Composition and formation of the sleeve enveloping a central venous catheter. J Vasc Surg 1998; 28: 260-71

30 - Cassidy F, Zajko A, Bron K, Reily J, Peitzman A, Steed D. Noninfectious complication of long-term central venous catheters: radiologic evaluation and management. Am J Radiol 1987;149:671-5.

31 - Bern M, Lockich J, Wallach S, Bothe A, Benotti P, Arkin C, Greco FA, Huberman M, Moore C. Very low doses of warfarin can prevent thrombosis in central venous catheters. Ann Intern Med 1990; 1112: 423-8.

32 - Masci G, Magagnoli M, Zucali PA, Castagna L, Carnaghi C, Sarina B, Pedicini V, Fallini M, Santoro A. Minidose warfarin prophilaxis for catheter-associated with fluorouracil-based chemotherapy. J Clin Oncol 2003; 21(4): 736-9.

33 - Polderman $\mathrm{KH}$, Girbes RJ. Central venous catheter use. Part 2: Infectious complications. Intensive Care Med. 2002; 28: $18-28$ 